\title{
Volatility-Spillover Effects in European Bond Markets ${ }^{1}$
}

\author{
Charlotte Christiansen ${ }^{2}$ \\ Aarhus School of Business
}

First Version: September 2003

This version: November 21, 2003

${ }^{1}$ Helpful comments and suggestions from colleagues, Tom Engsted, and Jesper Lund are appreciated.

${ }^{2}$ Charlotte Christiansen, Department of Finance, Aarhus School of Business, Fuglesangs Alle 4, 8210 Aarhus V, Denmark. Phone: +45 8948 6691, fax: +45 8615 1943, email: cha@asb.dk, homepage: www.asb.dk/ cha. 


\title{
Volatility-Spillover Effects in European Bond Markets
}

\begin{abstract}
We analyze volatility spillover from the US and aggregate European bond markets into individual European bond markets using a GARCH volatility-spillover model. We find strong statistical evidence of volatility-spillover effects from both the US and Europe into the individual bond markets. For the EMU countries, the US volatility-spillover effects are rather weak whereas the European volatility-spillover effects are strong. The opposite applies to the non-EMU countries. Pure local volatility effects are substantial. The introduction of the euro has strengthened the European volatility-spillover effects for the EMU countries. The non-EMU countries are unaffected hereby.
\end{abstract}

Keywords: Euro; GARCH; Government Bonds; International Bond Markets; VolatilitySpillover

JEL Classifications: C32; E43; F36; G12; G15 


\section{Introduction}

This paper is concerned with the effects of volatility spillover from the US and aggregate European bond markets to a number of European bond markets; Belgium, Denmark, France, Germany, Italy, the Netherlands, Spain, Sweden, and the UK. A volatility-spillover model is applied to separate the shock to the individual country return into three effects; A local (own country) effect, a regional (aggregate Europe) effect, and a global (US) effect. In contrast to related volatility-spillover studies, we focus on international bond markets. Thereby the study leads to interesting new insights into the nature of the volatility of the European bond markets.

The empirical analysis makes use of the J. P. Morgan government bond indices. The volatility-spillover model is based upon the models of Bekaert and Harvey (1997), Ng (2000), Bekaert, Harvey and Ng (forthcoming), and Baele (2002). The estimation is conducted in three steps. The first two steps model the returns of the US and European indices, respectively. The return on the individual-country indices are assumed to follow AR-GARCH processes (the third step). The one-period lagged US and European returns as well as the contemporary US and European residuals are added to the mean specification. Including the lagged US and European returns in the mean equation make room for mean-spillover effects. Including the US and European residuals in the mean equation enable volatility-spillover effects: Hereby the conditional volatility of the unexpected return is dependent on the variance of the contemporary US, European, and own idiosyncratic shocks. The conditional variance of the unexpected return is divided into the proportion caused by US effects, European effects, and own country effects.

For a start, it is assumed that the spillover effects are constant over time. We find only weak evidence of mean-spillover effects from the US and aggregate Europe to the individual bond markets. We find strong evidence of volatility-spillover effects from both the US and aggregate Europe to the individual bond markets. All the remaining empirical results group the countries into the EMU-member countries plus Denmark (EMU countries) and the non-EMU member countries. For the EMU countries the proportion of the variance of the unexpected return caused by US effects is rather small 
(1\%-2\%), whereas the proportion caused by European effects is quite large (44\%-65\%). The opposite applies to the non-EMU countries for which the comparable figures are $12 \%-23 \%$ and $10 \%-22 \%$. The own-country effects are larger for the non-EMU countries (about 66\%) than for the EMU countries (33\%-54\%). For the EMU countries the European volatility-spillover effects are increasing over time.

Subsequently, the spillover effects are allowed to be different (but constant) before and after the introduction of the euro. The mean-spillover effects appear to be unaffected by the introduction of the euro. For the EMU countries the US volatility-spillover effects are stronger before the euro than after the euro and the opposite applies to the European volatility-spillover effects. The results for the non-EMU countries are not susceptible to the introduction of the euro. It appears that neglecting the euro "breakpoint" amounts to averaging across the two periods.

The literature has used a number of alternative frameworks to analyze the interdependence of international asset markets. Here, we briefly consider studies of international bond markets. Ilmanen (1995) uses a linear regression model with local and global instruments to forecast the excess returns of long-term international bonds. The world factors turn out to be the more important factors. The international excess returns are highly correlated and there is evidence that international bond markets are integrated. Clare and Lekkos (2000) investigate the interaction between the US, UK, and German bond markets by using a VAR model with the short rates and the term-structure slopes as the endogenous variables. The variance of each of the term-structure slopes are found to be influenced by international factors as well as local factors. The international factors are more important in times of financial instability. Driessen, Melenberg and Nijman (2003) investigate the common factors in the US, German and Japanese bond markets using principal components analysis. For each country, they consider the excess returns of indices for five different maturity intervals. Five factors are sufficient: The first factor is the world level factor, the second and third factors are local level factors, and the fourth and fifth factors represent local changes in the steepness of the term structure. In contrast to Clare and Lekkos (2000), Driessen et al. (2003) find that the positive correlation be- 
tween bond markets is driven by the term structure levels, not by the term structure slopes. Laopodis (forthcomingb) applies a VAR model to describe the long-term interest rates of 8 countries. He finds that markets have become more integrated through the 1990s which has narrowed the scope for conducting monetary policy. Laopodis (forthcominga) applies multivariate GARCH models to analyze various subsets of the US and 6 European short rates. He finds evidence that the German dominance in the EMS has been weakened after the German reunification.

The volatility-spillover analysis was initiated by Engle, Ito and Lin (1990) who investigate the Yen/USD exchange rate. Evidence of volatility-spillover effects is found. Lin, Engle and Ito (1994) investigate the volatility spillover between the US and Japanese stock markets. The daytime return and volatility in one market is correlated with the overnight return and volatility in the other market, i.e. evidence of volatility-spillover effects. Eom, Subrahmanyam and Uno (2002) find strong volatility-spillover effects from the US to the Japanese swap market, but only weak effects going the opposite direction. Bekaert and Harvey (1997), Ng (2000), and Baele (2002) investigate volatility-spillover effects on various equity markets using similar volatilityspillover models. They all find evidence of volatility-spillover effects. Bekaert and Harvey (1997) investigate the volatility of emerging stock markets. They distinguish between global and local shocks. Ng (2000) finds evidence of volatility-spillover effects to various pacific basin stock markets from Japan (regional effects) and the US (global effects). Baele (2002) investigates the volatility-spillover effects from the US (global effects) and aggregate European (regional effects) stock markets into various individual European stock markets.

Related literature considers integration (in contrast to segmentation) of asset markets, cf. e.g. Bekaert and Harvey (1995) and Karolyi and Stulz (1996). Similarly, contagion analysis is somewhat related to studies of volatility-spillover effects, cf. e.g. King and Wadhwani (1990).

The remaining part of the paper is structured as follows. Section 2 provides a detailed description of the volatility-spillover model that we apply. In Section 3 the bond market data are described. Subsequently, the empirical findings are discussed in Section 4. Finally, Section 5 concludes. 


\section{The Empirical Volatility-Spillover Model}

Our empirical volatility-spillover model is based on the models specified by Bekaert and Harvey (1997), Ng (2000), Bekaert et al. (forthcoming), and Baele (2002) who all consider volatility-spillover effects on the international stock markets. In this section, we introduce in detail the model framework that we apply to analyze the volatility-spillover effects on the international bond markets.

The volatility-spillover model is estimated in three steps. We structure the presentation around these three steps. In the first step, a univariate AR-GARCH model is estimated for the US return. In the second step, an extended univariate AR-GARCH model is estimated for the aggregate European return. The US residual from the first-step regression is included as an explanatory variable. Finally, in the third step, a univariate extended AR-GARCH model for the return of the individual European country is estimated. Both the US and European residuals from the two first steps are included as explanatory variables. In this way, the model accommodates two sources of volatility-spillover effects. The multi-step estimation procedure provides consistent, but not necessarily efficient, estimates. For each European country we apply a new European index that excludes own-country bonds. These European indices are described in detail in Section 3 below.

The three-step estimation procedure is equivalent to the method applied by Bekaert et al. (forthcoming) which represents only practical differences to the two-step estimation procedure applied by $\mathrm{Ng}$ (2000) and Baele (2002). The two-step estimation procedure is as follows: In the first step, a bivariate GARCH model for the US and European returns is estimated. There are no volatility-spillover effects between the US and Europe. In an intermediate step, the US and European residuals are orthogonalized: The European innovation is driven by a purely idiosyncratic shock and the US idiosyncratic shock whereas the US innovation is purely idiosyncratic. In the second step, the US and European idiosyncratic shocks are used as explanatory variables in the model for the return of the individual country. So, in fact, the two-step procedure also consists of three steps. The three-step estimation procedure distinguishes itself by allowing volatility-spillover effects from the US to Eu- 
rope and avoiding orthogonalization.

The subsequent analysis (of what will be denoted "variance ratios") relies on using the US and European idiosyncratic shocks as explanatory variables. Thus, the recursive model structure applied in the previous literature is necessary - either the explicit recursive structure in the three-step procedure or the implicit recursive structure obtained by orthogonalization in the two-step procedure. We let the causality go from the US to Europe. Apart from the intuitive appeal of moving from world effects to regional effects, the fact that we include spillover effects from the US to Europe and not the other way round is supported by Granger causality tests, cf Granger (1969). Granger causality tests with four lags are applied pairwise to the US return on the one side and the European indices each excluding one country on the other side. The European returns all fail to Granger cause the US return, whereas the US return Granger causes the European returns. ${ }^{1}$ Only for the European index excluding the UK is the conclusion different, namely that neither index Granger causes the other.

The conditional return on the US index is assumed to evolve according to an $\operatorname{AR}(1)$ process: ${ }^{2}$

$$
R_{U S, t}=c_{0, U S}+c_{1, U S} R_{U S, t-1}+e_{U S, t}
$$

The idiosyncratic shock $\left(e_{U S, t}\right)$ is normally distributed with mean 0 and the conditional variance follows a symmetric GARCH(1,1) specification, cf. Engle (1982) and Bollerslev (1986):

$$
\sigma_{U S, t}^{2}=\omega_{U S}+\alpha_{U S} e_{U S, t-1}^{2}+\beta_{U S} \sigma_{U S, t-1}^{2}
$$

where $\omega_{U S}>0$ and $\alpha_{U S}, \beta_{U S} \geq 0$ to make sure the variance is positive, and $\alpha_{U S}+\beta_{U S} \leq 1$ to ensure stationarity.

The return on the European index is assumed to be described by the following extended $\mathrm{AR}(1)$ specification:

$$
R_{E, t}=c_{0, E}+c_{1, E} R_{E, t-1}+\gamma_{E, t-1} R_{U S, t-1}+\phi_{E, t-1} e_{U S, t}+e_{E, t} .
$$

\footnotetext{
${ }^{1}$ Unless otherwise stated, a $5 \%$ level of significance is applied.

${ }^{2}$ The lag order of the AR specification is chosen in consideration of simplicity.
} 
The conditional mean of the European return depends on the its own lagged return as well as the lagged US return. The mean spillover effects are introduced by the lagged US return, $R_{U S, t-1}$ (i.e. the first AR extension). The volatility spillover from the US to Europe takes place via the penultimate term, $e_{U S, t}$ (i.e. the second AR extension). Thus, the European return depends on the US idiosyncratic shock. We will return to why this represents a volatility-spillover effect. In the practical estimation, the residual from equation (1) is used in place of $e_{U S, t}$. The idiosyncratic shock $\left(e_{E, t}\right)$ has mean 0 and the conditional variance evolves according to the $\operatorname{GARCH}(1,1)$

$$
\sigma_{E, t}^{2}=\omega_{E}+\alpha_{E} e_{E, t-1}^{2}+\beta_{E} \sigma_{E, t-1}^{2}
$$

where we again require that $\omega_{E}>0, \alpha_{E}, \beta_{E} \geq 0$, and $\alpha_{E}+\beta_{E} \leq 1$.

The last step consists in providing a model for the individual country returns. The mean specification for the European return in equation (3) is extended even further. For country $i(i=1, \ldots, N)$ :

$$
\begin{aligned}
R_{i, t} & =c_{0, i}+c_{1, i} R_{i, t-1}+\gamma_{i, t-1} R_{U S, t-1}+\delta_{i, t-1} R_{E, t-1} \\
& +\phi_{i, t-1} e_{U S, t}+\psi_{i, t-1} e_{E, t}+e_{i, t}
\end{aligned}
$$

The conditional country $i$ mean return depends on the lagged US, European, and own return. This specification allows mean spillover effects from both the US and European returns to the individual countries by the lagged returns $R_{U S, t-1}$ and $R_{E, t-1}$. Volatility-spillover effects from the US and Europe to the individual countries are introduced by the variables $e_{U S, t}$ and $e_{E, t}$, respectively, i.e. the idiosyncratic US and European shocks. Shortly, it will become clear exactly why this corresponds to volatility-spillover effects, cf. equation (10) below. In the estimation, the residuals from equations (1) and (3) are applied as explanatory variables. The idiosyncratic country shocks are subject to the same distributional assumptions as the other idiosyncratic shocks; they have mean 0 and the following conditional volatility:

$$
\sigma_{i, t}^{2}=\omega_{i}+\alpha_{i} e_{i, t-1}^{2}+\beta_{i} \sigma_{i, t-1}^{2}
$$

where $\omega_{i}>0, \alpha_{i}, \beta_{i} \geq 0$, and $\alpha_{i}+\beta_{i} \leq 1$. 
The idiosyncratic shocks $e_{U S, t}, e_{E, t}$, and $e_{i, t}$ (for $i=1, \ldots, N$ ) are assumed to be independent. This, however, does not apply for the unexpected returns:

$$
\begin{aligned}
\epsilon_{U S, t} & =e_{U S, t} \\
\epsilon_{E, t} & =\phi_{E, t-1} e_{U S, t}+e_{E, t} \\
\epsilon_{i, t} & =\phi_{i, t-1} e_{U S, t}+\psi_{i, t-1} e_{E, t}+e_{i, t-1} .
\end{aligned}
$$

The definitions of the unexpected returns in equations (7) to (9) enable us to calculate the conditional variance of the unexpected return for country $i$, as well as the conditional covariances and correlations between the unexpected returns.

The conditional variance of the unexpected return of country $i$ based on the information available at time $t-1\left(I_{t-1}\right)$ is given as follows.

$$
h_{i t}=\mathrm{E}\left(\epsilon_{i, t}^{2} \mid I_{t-1}\right)=\phi_{i, t-1}^{2} \sigma_{U S, t}^{2}+\psi_{i, t-1}^{2} \sigma_{E, t}^{2}+\sigma_{i, t}^{2} .
$$

The conditional variance of the unexpected return for country $i$ depends on the variance of the contemporary US, European, and own idiosyncratic shocks. When e.g. the US idiosyncratic volatility is large, the volatility of the unexpected returns for country $i$ also tends to be large (small) if $\phi_{i, t-1}$ is positive (negative). This is what we denote volatility-spillover effects. So, the sign and significance of the parameters $\phi_{i, t-1}$ and $\psi_{i, t-1}$ determine whether volatility-spillover effects from the US and Europe, respectively, are present in country $i$. The conditional variance of the European unexpected return depends only on the US and its own idiosyncratic volatility (equation not provided). The conditional variance of the US unexpected return is equal to the variance of the US idiosyncratic shock.

The conditional covariance between the unexpected return of country $i$ and the US (European) unexpected return depends on the US (US and European) idiosyncratic volatilities:

$$
\begin{aligned}
h_{i U S, t} & =\mathrm{E}\left(\epsilon_{i, t} \epsilon_{U S, t} \mid I_{t-1}\right)=\phi_{i, t-1} \sigma_{U S, t}^{2} \\
h_{i E, t} & =\mathrm{E}\left(\epsilon_{i, t} \epsilon_{E, t} \mid I_{t-1}\right)=\phi_{i, t-1} \phi_{E, t-1} \sigma_{U S, t}^{2}+\psi_{i, t-1} \sigma_{E, t}^{2} .
\end{aligned}
$$


The conditional covariance between the unexpected return of country $i$ and $j$ also depends on the US and European idiosyncratic volatility:

$$
h_{i j, t}=\mathrm{E}\left(\epsilon_{i, t} \epsilon_{j, t} \mid I_{t-1}\right)=\phi_{i, t-1} \phi_{j, t-1} \sigma_{U S, t}^{2}+\psi_{i, t-1} \psi_{j, t-1} \sigma_{E, t}^{2} .
$$

The conditional covariance between the US and European unexpected returns depends only on the US idiosyncratic volatility:

$$
h_{E U S, t}=\mathrm{E}\left(\epsilon_{E, t} \epsilon_{U S, t} \mid I_{t-1}\right)=\phi_{E, t-1} \sigma_{U S, t}^{2}
$$

The conditional correlations between the unexpected returns of country $i$ and the US (Europe) depends on the US (US and European) idiosyncratic volatilities as follows:

$$
\begin{aligned}
\rho_{i U S, t} & =\frac{h_{i U S, t}}{\sqrt{h_{i, t} h_{U S, t}}}=\frac{\phi_{i, t-1} \sigma_{U S, t}}{\sqrt{h_{i, t}}} \\
\rho_{i E, t} & =\frac{h_{i E, t}}{\sqrt{h_{i, t} h_{E, t}}}=\frac{\phi_{i, t-1} \phi_{E, t-1} \sigma_{U S, t}^{2}+\psi_{i, t-1} \sigma_{E, t}^{2}}{\sqrt{h_{i, t} h_{E, t}}} .
\end{aligned}
$$

We want to measure the proportion of the variance of the unexpected return of country $i$, cf. equation (10), that is caused by the US and European volatility-spillover effects, respectively. To this end, we define the following variance ratios:

$$
\begin{aligned}
V R_{i, t}^{U S} & =\frac{\phi_{i, t-1}^{2} \sigma_{U S, t}^{2}}{h_{i, t}} \\
V R_{i, t}^{E} & =\frac{\psi_{i, t-1}^{2} \sigma_{E, t}^{2}}{h_{i, t}} .
\end{aligned}
$$

The variance ratios take on values between 0 and 1 . The remaining part of the variance of the unexpected return for country $i$ is caused by pure local effects;

$$
V R_{i, t}^{i}=1-V R_{i, t}^{U S}-V R_{i, t}^{E}=\frac{\sigma_{i, t}^{2}}{h_{i, t}}
$$

From the variance ratios we get a measure of the impact of global, regional, and local effects on the local variance.

The specification of the functions for the spillover parameters, $\gamma_{t}, \delta_{t}, \phi_{t}$, and $\psi$ differentiates the various volatility-spillover models. Some models use 
linear regression functions with exogenous variables such as trade variables to describe the spillover parameters. Other models adopt pure time series models. Here we apply the latter approach. Either, the spillover parameters are assumed to be constant throughout the entire sample period; the constant spillover model:

$$
\begin{aligned}
\gamma_{i, t} & =\gamma_{i} \forall t \\
\delta_{i, t} & =\delta_{i} \forall t \\
\phi_{i, t} & =\phi_{i} \forall t \\
\psi_{i, t} & =\psi_{i} \forall t .
\end{aligned}
$$

Or, the spillover parameters are assumed to be constant in two sub periods; before and after the introduction of the euro; the euro spillover model:

$$
\begin{aligned}
\gamma_{i, t} & =\gamma_{0, i}+\gamma_{1, i} D_{t} \\
\delta_{i, t} & =\delta_{0, i}+\delta_{1, i} D_{t} \\
\phi_{i, t} & =\phi_{0, i}+\phi_{1, i} D_{t} \\
\psi_{i, t} & =\psi_{0, i}+\psi_{1, i} D_{t} .
\end{aligned}
$$

The dummy variable $D_{t}$ equals 0 before January 1 , 1999 (i.e. before the introduction of the euro) and 1 after January 1, 1999.

\section{The Data}

We apply the J. P. Morgen total return government bond indices extracted from DataStream for the US, Europe, six EU EMU-member countries (Belgium, France, Germany, Italy, the Netherlands, and Spain), and three EU non-EMU member countries (Denmark, Sweden, and UK). "Total return" implies that the received coupons are invested back into the bonds of the index. Log-returns are calculated as the logarithmic growth rate of the indices. ${ }^{4}$ All returns are measured in a common currency, namely DEM. Thus,

\footnotetext{
${ }^{3}$ J. P. Morgan does not provide government bond indices for other European countries.

${ }^{4}$ We follow the previous literature in applying log-returns of total return government bond indices, cf. e.g. Bodart and Reding (1999) and Driessen et al. (2003).
} 
the returns are currency hedged and we take the viewpoint of a German investor. In contrast, returns in local currency are unhedged against currency risk. ${ }^{5}$ The weekly data (sampled on Wednesdays) cover the period from January 6, 1988 to November 27, 2002, thus, providing us with a total of 777 observations.

Using weekly data (compared to e.g. daily data) partially overcomes the potential problem of non-synchronous data, cf. Burns and Engle (1998). In stable periods, close-to-close (i.e. non-synchronous) daily returns on international stock markets tend to underestimate correlations, cf. Martens and Poon (2001). If this carries over to weekly returns on international bond markets, it might suggest that the hypothesis of no spillover effects is accepted too often. This would mean that the proposition of spillover effects is not wrongly accepted on this account.

The European index is a (market value) weighted average of the indices of the nine European countries. Thus, there is spurious correlation between the individual country return and the European return caused by the same bonds being included in both indices. Therefore, for each country, we calculate the return of an artificial European index excluding the country itself, cf. Bekaert et al. (forthcoming). We use the weights that J. P. Morgan applied in January 2002 for the European index, cf. Diamond, Simons and Sanders (2002). ${ }^{6}$ The artificial European index for all nine countries is very strongly correlated with the J. P. Morgan European index (the correlation coefficient is in excess of $95 \%$ ), thus, we find it safe to apply constant weights.

Table 1 contains summary statistics for the returns of the nine country indices as well as the US and European indices. The average weekly returns fall in a fairly tight range; from $0.13 \%$ (Germany) to $0.18 \%$ (Italy and the US). The variability of the returns is much more dispersed across the indices; the standard deviation of the weekly return falls in the interval between $0.24 \%$ (Germany) and 1.53 (the US). Generally, the return of the index tends to be more variable the higher its average return. Apart from the US, the return distributions are skewed to the left, and all the distributions show excess

\footnotetext{
${ }^{5}$ Volatility-spillover analysis generally apply common currency returns, cf. e.g. Bekaert et al. (forthcoming).

${ }^{6}$ We have only access to this set of weights.
} 
kurtosis. Therefore the Jarque and Bera (1980) test rejects normality for all the series. Some of the return series are significantly autocorrelated (Ljung and Box (1978) tests for first order and up to fourth order autocorrelation). Thus, there are indications that the AR specification is useful. The squared return series are significantly autocorrelated - again, with the exception of the UK (Ljung and Box (1978) tests for first order and up to fourth order autocorrelation). Thus, the presence of heteroskedasticity motivates the GARCH specifications.

\section{Empirical Findings}

We estimate the spillover model in three steps using the Quasi Maximum Likelihood (QML) method with (univariate) Gaussian likelihood functions. The estimation is conducted using a combination of the Berndt, Hall, Hall and Hausman (1974) and the Newton-Raphson numerical optimization algorithm. $^{7}$

\subsection{Constant Spillover Model}

Table 2 reports the results from estimating the constant spillover model. In the first step, the univariate model for the US return is estimated, cf. the first row of Table 2. The $\mathrm{AR}(1)$ parameter $\left(\hat{c}_{1, i}\right)$ is small, negative, and insignificant, which implies no (or weak negative) first-order autocorrelation, consistent with the summary statistics reported in Table 1 . The volatility process is quite persistent in that $\hat{\alpha}_{U S}+\hat{\beta}_{U S}$ roughly equals 0.9 .

We investigate the properties of the standardized residuals, $\frac{\hat{e}_{U S, t}}{\hat{\sigma}_{U S, t}}$, to evaluate the appropriateness of the model. If the model is well specified, the standardized residuals have mean zero, unit variance, are serially uncorrelated, and no ARCH effects remain. In addition, the series of the squared standardized residuals are serially uncorrelated. We apply the Ljung and Box (1978) Q-test for no autocorrelation up to orders 1 and 4, respectively, and the Lagrange Multiplier test for no ARCH(1) effects, cf Engle (1982).

\footnotetext{
${ }^{7}$ The estimation is conducted in GAUSS using the Constrained Maximum Likelihood module.
} 
Based on these seven specification tests, we find no signs that the model for the return of the US index is misspecified.

The second row of Table 2 reports the results from the second step of the estimation of the constant spillover model, namely for the return of the European index. Notice that only the results for the European index including all nine countries are reported. The results for the nine artificial European indices excluding one country each are similar here to. Own lagged and US lagged returns are of minor importance to the conditional mean; $\hat{c}_{1, E}$ and $\hat{\gamma}_{E}$ are small, positive, and insignificant. In contrast, the contemporaneous US residual is significant in explaining the current mean value. Thus, there is evidence of volatility-spillover from the US to the European bond market, i.e. $\hat{\phi}_{E}$ is significantly positive, but no evidence of mean spillover, i.e. $\hat{\gamma}_{E}$ is insignificant. The robust joint Wald test for no US-spillover effects at all, $\mathrm{H}_{0}$ : $\gamma_{E}=\phi_{E}=0$, is strongly rejected. The volatility process is highly persistent $\left(\hat{\alpha}_{E}+\hat{\beta}_{E}=0.97\right)$. The model for the return on the European index appears to be well specified. This statement is based upon the seven specification tests from above applied to the European standardized residuals.

In the last step, the models for the individual countries are estimated. The models include mean and volatility-spillover effects from both the US and Europe. For each country we apply the artificial European index that excludes the country itself. ${ }^{8}$ The bottom rows of Table 2 provide the results here from. For all countries, the returns show negative or no first-order autocorrelation. The conditional volatility processes are highly persistent. In fact, in most cases the restriction that $\alpha_{i}+\beta_{i} \leq 1$ is binding (the exceptions are Germany, Sweden, and the UK). This implies that the conditional variances evolve according to Integrated GARCH processes.

Table 3 provides the robust Wald tests for five different joint hypotheses regarding spillover effects. The US mean-spillover parameter, $\hat{\gamma}_{i}$, tends to be positive. Still, only in few countries (Germany and the Netherlands), do we find significant US mean-spillover effects (and that only at the $10 \%$ level of significance). For around half of the countries, there is evidence of European mean-spillover effects, i.e. $\hat{\delta}_{i}$ is positive and significant. The robust Wald

\footnotetext{
${ }^{8}$ This means that the values of $R_{E, t-1}$ and $\hat{e}_{E, t}$ that enter into the mean equation of the return to country $i$ is different for each country.
} 
test for the joint hypothesis of no mean-spillover effects $\left(\mathrm{H}_{0}^{1}: \gamma_{i}=\delta_{i}=0\right)$ leaves the conclusions unaltered; for around half of the countries (the same as before) there are significant mean-spillover effects.

For all the countries there are significant volatility-spillover effects from both the US and Europe, i.e $\hat{\phi}_{i}$ and $\hat{\psi}_{i}$ are positive and individually significant. The robust Wald tests for the joint hypothesis of no volatility-spillover effects, $\mathrm{H}_{0}^{2}: \phi_{i}=\psi_{i}=0$, is rejected for all the countries.

The results also lead us to reject the null hypotheses of no US-spillover effects $\left(\mathrm{H}_{0}^{3}: \gamma_{i}=\phi_{i}=0\right)$ as well as no European-spillover effects $\left(\mathrm{H}_{0}^{4}: \delta_{i}=\right.$ $\left.\psi_{i}=0\right)$ for all the countries. Finally, the null hypothesis of no spillover effects at all is rejected in all cases: $\mathrm{H}_{0}^{5}: \gamma_{i}=\delta_{i}=\phi_{i}=\psi_{i}=0$.

To summarize, there are very strong indications of volatility-spillover effects from both the US and European bond markets into all the individual bond markets, less strong indications of mean-spillover effects from the European market, and only very weak signs of mean-spillover effects from the US market.

So far, we have only discussed the sign and significance of the spillover parameters. The relative size of the parameters are not particularly relevant to evaluate the quantitative influence of the US and European bond markets on the individual bond markets. To access the importance of the US and European volatility-spillover effects on the variance of the unexpected return of country $i$, the time series of the variance ratios $V R_{i, t}^{U S}, V R_{i, t}^{E}$, and $V R_{i, t}^{i}$ from equations (17)-(19) are calculated. Table 4 reports the mean of the variance ratios for each country. Over the period on average the US volatilityspillover effects make up between $0.8 \%$ and $23.1 \%$ of the conditional variance of the unexpected return of country $i$. For most countries the mean of the US variance ratio is around $1 \%-2 \%$, only in two cases is it considerably higher; Sweden $(12 \%)$ and the UK $(23 \%)$. It is remarkable, that the US volatilityspillover effects are particularly strong for two out of three non-EMU member countries (Denmark is the exception). On average the European variance ratio amounts to between $44 \%$ and $65 \%$ for the EMU-member countries plus Denmark, whereas, the European variance ratio for Sweden and the UK is much smaller (means of $22 \%$ and $10 \%$, respectively). Finally, the pure local volatility effects are larger for Sweden and the UK (means of $66 \%$ and $67 \%$ ) 
than for the other countries (the means range between $33 \%$ and $54 \%$ ).

To all intents and purposes Denmark behaves like an EMU-member country because the Danish central bank pegs the Danish Krone to the euro.

Figure 1 to Figure 9 show the time series evolution of the variance ratios for each of the nine countries. It is noticed that the European variance ratio is generally increasing over the sample period for all countries except (again) Sweden and the UK, for which it appears to be stable.

Summing up, with a couple of non-EMU exceptions, the US variance is of limited importance to the variance of the unexpected return of country $i$, whereas the European variance is of strong and increasing importance here to.

The results regarding the relative size of volatility-spillover effects from the US and aggregate European bond markets into EMU and non-EMU bond markets compare well to the results for the corresponding stock markets, cf. Baele (2002). Due to differences in scope (and methodology), our results are not directly comparable to the previous results regarding bond market interdependencies. Our findings appear to be in contrast to those of Ilmanen (1995) who find that world factors are more important than local factors. Our results appear to be in accordance with those of Clare and Lekkos (2000) who find that both international and local factors influence bond returns.

In the analysis we have applied the European indices excluding the country under investigation. Using instead the all-inclusive European index affects the size of the variance ratios: The mean of the US variance ratio tends to be larger, whereas the own idiosyncratic variance part tends to be smaller.

As a robustness check, we redo the analysis excluding any insignificant parameters that enter into the first two steps of the estimation of the constant spillover model. In the first step, we impose the restriction that $c_{1, U S} \equiv 0$, which does not alter the subsequent results. Therefore, in the second step, we let $c_{1, E} \equiv \gamma_{E} \equiv 0$. This does not alter the empirical results for the individual countries (i.e. the third step). It is stressed that the variance ratios are almost completely unchanged.

The appropriateness of the model specification for the return of each country's index is accessed by applying to the standardized residuals the seven specification tests introduced above. Only five out of 63 hypotheses 
are rejected. ${ }^{9}$ Therefore, the model appears to be reasonably specified.

\subsection{Euro Spillover Model}

The euro spillover model implies that the spillover parameters take on constant - possibly different - values before and after the introduction of the euro, cf. equation (21). Table 5 contains the results from estimating the euro spillover model. The estimates of the GARCH parameters $\left(\omega_{i}, \alpha_{i}\right.$, and $\beta_{i}$ ) are not reported because they are similar to the results of the constant spillover model.

The univariate model for the US return (i.e. the first step of the estimation of the euro spillover model) is identical to that of the constant spillover model; for convenience the results are repeated in the first row of Table 5 .

The second step of the estimation concerns the return of the European bond index, cf. the second row of Table 5. Only the results for the allinclusive European index are reported. For the all-inclusive index there are no changes in the US mean-spillover effects after the euro ( $\hat{\gamma}_{1, E}$ is insignificant), whereas the US volatility-spillover effects have decreased after the euro $\left(\hat{\phi}_{1, E}\right.$ is significantly negative). The joint hypothesis of no spillover changes after the euro is rejected; the robust Wald test for the hypothesis $\mathrm{H}_{0}: \gamma_{1, E}=$ $\phi_{1, E}=0$ results in a p-value equal to $4.7 \%$.

For the nine European indices excluding one country each, there is no evidence that the spillover effects are different after the euro. The subsequent results are robust to including or excluding euro changes in the spillover parameters, i.e. imposing or not imposing the restriction that $\gamma_{1, E} \equiv \phi_{1, E} \equiv$ 0 . Thus, we continue with the original spillover specification for the European return.

In the third step of the estimation, we investigate the effect of the euro on the mean-spillover effects and the volatility-spillover effects from the US and European bond markets to the individual European bond markets, cf. the bottom rows of Table 5 . As for the constant spillover model, we only find

\footnotetext{
${ }^{9}$ The five instances are: France: The p-value for $\mathrm{AC}(4)$ equals $0.8 \%$, the p-value of $\mathrm{AC}^{2}(4)$ equals $0.5 \%$. Italy: The p-value for unit variance equals $0.3 \%$. The Netherlands: The p-value for AC(4) equals $0.2 \%$. Spain: The p-value for ARCH(1) equals $2.3 \%$.
} 
scattered evidence of mean spillover effects. For the period before the euro there are only mean-spillover effects for few countries, $\hat{\gamma}_{0, i}$ and $\hat{\delta}_{0, i}$ are only significantly positive for few countries. Moreover, there is no evidence that the mean-spillover effects are different after the euro; for all the countries we reject the hypothesis $\mathrm{H}_{0}: \gamma_{1, i}=\delta_{1, i}=0$. After the euro, there are still almost no signs of mean-spillover effects; we cannot reject $\mathrm{H}_{0}: \gamma_{0, i}=\gamma_{1, i}=\delta_{0, i}=$ $\delta_{1, i}=0$ for all $i$ save Belgium for which the p-value equals $0.4 \%$.

There are strong indications of both US and European volatility-spillover effects. For the period before the euro the US volatility-spillover effects as well as the European volatility-spillover effects are significant, i.e. $\phi_{0, i}$ and $\psi_{\mathbf{0}, i}$ are significantly positive. In addition, the volatility-spillover effects are significantly different after the euro, the robust Wald test for the hypothesis $\mathrm{H}_{0}: \phi_{1, i}=\psi_{1, i}=0$ is rejected for all countries. There are also significant volatility-spillover effects after the euro; $\mathrm{H}_{0}: \phi_{0, i}=\phi_{1, i}=\psi_{0, i}=\psi_{1, i}=0$ is rejected for all $i$.

For the EMU countries plus Denmark the following commonalities are observed. The US volatility-spillover effects before the euro are found to be stronger than the effects estimated by the constant spillover model, i.e. $\hat{\phi}_{\mathbf{0}, i}>$ $\hat{\phi}_{i}$. The US volatility-spillover effects are dampened by the euro $\left(\hat{\phi}_{1, i}<0\right)$ and are weaker than estimated by the constant spillover model, $\hat{\phi}_{0, i}+\hat{\phi}_{1, i}<\hat{\phi}_{i}$. In contrast, the European volatility-spillover effects before the euro are found to be weaker than estimated by the constant spillover model; $\hat{\psi}_{\mathbf{0}, i}<\hat{\psi}_{i}$. After the euro, the effects of European volatility-spillover are strengthened $\left(\hat{\psi}_{1, i}>0\right)$ and are stronger than estimated by the constant spillover model, $\hat{\psi}_{0, i}+\hat{\psi}_{1, i}>\hat{\psi}_{i}$. Not taking the introduction of the euro into account when considering volatility-spillover effects appears to be identical to averaging across the two time periods. These observations, however, do not apply for Sweden and the UK. The US volatility-spillover effects are unaltered (Sweden) or strengthened (UK) by the euro, whereas the European volatilityspillover effects are dampened by the euro.

Table 6 presents the mean of the variance ratios. Sweden and the UK are again exceptions that we will return to. Compared to the constant spillover model, the mean of the US variance ratio has increased from $1 \%-2 \%$ to $2 \%$ $6 \%$. The means of the European variance ratios tend to be smaller in the 
euro spillover model than in the constant spillover model. On average the US variance makes up a larger proportion of the variance of the unexpected return to country $i$ because the sample period before the euro is longer than the sample period after the euro. This can also be seen from the time series plots of the variance ratios shown in Figure 10 to Figure 18. For Sweden and the UK the means of the US and European variance ratios are almost unaltered. This is not surprising provided that the euro appears to be an insignificant event for the spillover processes for these non-EMU countries.

To access the validity of the euro spillover model we investigate the standardized residuals. There are no problems for the US and European indices. For the individual country indices there are nine (out of 63) breaches of the assumptions. ${ }^{10}$ Thus, we find it safe to trust the results.

\section{Conclusion}

In this paper we have considered how the volatility in a number of European bond markets are affected by the volatility in the US and European bond markets. We have distinguished between global, regional, and local volatility effects. We have applied a GARCH-type model that allows for both mean and volatility spillover from the US and aggregate European bond markets into the individual countries. Mean-spillover effects have appeared to be almost negligible, whereas volatility spillover effects have appeared to be essential. For the EMU countries (plus Denmark) regional effects have been shown to be most important followed by local effects. Global effects have been shown to be almost inconsequential. For non-EMU countries own country effects have been found to be stronger, European effects smaller and US effects larger. The EMU countries have been shown to be less affected by the US bond market after the introduction of the euro.

We have found evidence that there are substantial differences between the

\footnotetext{
${ }^{10}$ The nine instances are: Belgium: The p-value for $\mathrm{AC}(4)$ equals $3.6 \%$, the p-value for $\mathrm{ARCH}(1)$ equals $2.1 \%$. Germany: The p-value for $\mathrm{AC}(4)$ equals $0.7 \%$, the p-value for $\mathrm{AC}^{2}(4)$ equals $0.3 \%$. Italy: The p-value for unit variance equals $0.1 \%$. The Netherlands: The $\mathrm{p}$-value for unit variance equals $0.9 \%$, the $\mathrm{p}$-value for $\mathrm{AC}(1)$ equals $0.4 \%$, the $\mathrm{p}$-value for $\mathrm{AC}(4)$ equals $0.0 \%$. Spain: The p-value for $\mathrm{ARCH}(1)$ equals $4.2 \%$.
} 
nature of the volatility of the bond markets of EMU-member countries and of non-EMU member countries. Still, we have only considered "old" European bond markets, not the emerging bond markets. Thus, one can only speculate as to how the "new" bond markets differ from the established bond markets in this respect. At the moment, data constraints prevent us from conducting this interesting exercise. 


\section{References}

Baele, L. (2002), Volatility Spillover Effects in European Equity Markets: Evidence from a Regime Switching Model, Working paper, Ghent University.

Bekaert, G. and Harvey, C. R. (1995), 'Time-Varying World Market Integration', Journal of Finance 50(2), 403-444.

Bekaert, G. and Harvey, C. R. (1997), 'Emerging Equity Market Volatility', Journal of Financial Economics 43, 29-77.

Bekaert, G., Harvey, C. R. and Ng, A. (forthcoming), 'Market Integration and Contagion', Journal of Business .

Berndt, E. K., Hall, B. H., Hall, R. E. and Hausman, J. A. (1974), 'Estimation and Inference in Nonlinear Structural Models', Annals of Economic and Social Measurement 3, 653-665.

Bodart, V. and Reding, P. (1999), 'Exchange Rate Regime, Volatility and International Correlations on Bond and Stock Markets', Journal of International Money and Finance 18, 133-151.

Bollerslev, T. (1986), 'Generalized Autoregressive Conditional Heteroskedasticity', Journal of Econometrics 31, 307-327.

Bollerslev, T. and Wooldridge, J. M. (1992), 'Quasimaximum Likelihood Estimation Dynamic Models with Time Varying Covariances', Econometric Reviews 11, 143-172.

Burns, P. and Engle, R. (1998), 'Correlations and Volatilities of Asynchronous Data', Journal of Derivatives 5(4), 7-18.

Clare, A. and Lekkos, I. (2000), An Analysis of the Relationship between International Bond Markets, Working paper, Bank of England.

Diamond, F., Simons, J. and Sanders, D. (2002), J. P. Morgan Government Bond Indices, Portfolio Research report, J. P. Morgan. 
Driessen, J., Melenberg, B. and Nijman, T. (2003), 'Common Factors in International Bond Returns', Journal of International Money and Finance $\mathbf{2 2}(5), 629-656$.

Engle, R. F. (1982), 'Autoregressive Conditional Heteroskedasticity with Estimates of the Variance of United Kingdom Inflation', Econometrica 50, 987-1007.

Engle, R. F., Ito, T. and Lin, W.-L. (1990), 'Meteor-Showers or Heat Waves? Heteroskedastic Intro-Daily Volatility in the Foreign Exchange Market', Econometrica 58(3), 525-542.

Eom, Y. H., Subrahmanyam, M. G. and Uno, J. (2002), 'The Transmission of Swap Spreads and Volatilities in the International Swap Markets', Journal of Fixed Income 12(1), 6-28.

Granger, C. W. (1969), 'Investigating Causal Relations by Econometric Models and Cross-Spectral Methods', Econometrica 37, 424-438.

Ilmanen, A. (1995), 'Time-Varying Expected Returns in International Bond Markets', Journal of Finance 50(2), 481-506.

Jarque, C. M. and Bera, A. K. (1980), 'Efficient Tests for Normality', Economics Letters 6, 255-259.

Karolyi, G. A. and Stulz, R. M. (1996), 'Why Do Markets Move Together? An Investigation of US-Japan Stock Return Comovements', Journal of Finance 51(3), 951-986.

King, M. A. and Wadhwani, S. (1990), 'Transmission of Volatility between Stock Markets', Review of Financial Studies 3(1), 5-33.

Laopodis, N. T. (forthcominga), 'European and International Asymmetry in the Volatility Transmission Mechanism: The "German Dominance Hypothesis" Revisited', Journal of Economics and Business .

Laopodis, N. T. (forthcomingb), 'Monetary Policy Implications of Comovements among Long-Term Interest Rates', Journal of International Financial Markets, Institutions, $\mathscr{G}$ Money . 
Lin, W.-L., Engle, R. F. and Ito, T. (1994), 'Do Bulls and Bears Move across Borders? International Transmission of Stock Returns and Volatility', Review of Financial Studies 7(3), 507-538.

Ljung, G. M. and Box, G. E. P. (1978), 'On a Measure of Lack of Fit in Time-Series Models', Biometrika 65, 297-3003.

Martens, M. and Poon, S.-H. (2001), 'Returns Synchronization and Daily Correlation Dynamics between International Stock Markets', Journal of Banking \& Finance 25, 1805-1827.

Ng, A. (2000), 'Volatility Spillover Effects from Japan and the US to the Pacific-Basin', Journal of International Money and Finance 19, 207233. 


\begin{tabular}{lllllllll}
\hline & Mean & Stdev. & Skew. & Kurt. & $\mathrm{AC}(1)$ & $\mathrm{AC}(4)$ & $\mathrm{AC}^{2}(1)$ & $\mathrm{AC}^{2}(4)$ \\
\hline $\mathrm{US}$ & 0.18 & 1.53 & 0.13 & 3.91 & -0.05 & 0.04 & 0.03 & $0.05^{*}$ \\
$\mathrm{Eu}$ & 0.15 & 0.59 & -0.57 & 5.38 & -0.02 & -0.00 & $0.08 \S$ & $0.09^{*}$ \\
$\mathrm{Be}$ & 0.16 & 0.58 & -0.37 & 5.21 & -0.05 & $-0.09^{*}$ & $0.20^{*}$ & $0.19^{*}$ \\
$\mathrm{De}$ & 0.17 & 0.69 & -0.39 & 6.18 & 0.05 & 0.01 & $0.18^{*}$ & $0.14^{*}$ \\
$\mathrm{Fr}$ & 0.16 & 0.66 & -0.11 & 4.65 & -0.02 & -0.04 & $0.11^{*}$ & $0.13^{*}$ \\
$\mathrm{Ge}$ & 0.13 & 0.48 & -0.65 & 4.65 & 0.03 & $-0.01 \S$ & $0.14^{*}$ & $0.11^{*}$ \\
$\mathrm{It}$ & 0.18 & 1.23 & -1.18 & 15.0 & 0.06 & $-0.02^{*}$ & $0.20^{*}$ & $0.11^{*}$ \\
$\mathrm{Ne}$ & 0.13 & 0.53 & -0.63 & 4.63 & 0.00 & $0.06 \S$ & $0.11^{*}$ & $0.14^{*}$ \\
$\mathrm{Sp}$ & 0.17 & 0.97 & -0.73 & 9.78 & -0.04 & -0.04 & $0.14^{*}$ & $0.12^{*}$ \\
$\mathrm{Sw}$ & 0.15 & 1.39 & $-0,42$ & 5.66 & -0.06 & $0.10 \S$ & $0.19^{*}$ & $0.07^{*}$ \\
$\mathrm{UK}$ & 0.19 & 1.34 & -0.12 & 3.94 & -0.02 & 0.01 & 0.05 & -0.02
\end{tabular}

The table reports the summary statistics for the weekly returns (in \%) of the J. P. Morgen government bond indices for the US, Europe (Eu), Belgium (Be), Denmark (De), France (Fr), Germany (Ge), Italy (It), the Netherlands (Ne), Spain (Sp), Sweden (Sw), and the UK. The following statistics are reported: Mean, standard deviation, skewness, kurtosis, autocorrelation (order 1 and 4), and autocorrelation of the squared time series (order 1 and 4). * (§) [\#] indicates that the Ljung and Box (1978) test statistic is significant at a $1 \%(5 \%)[10 \%]$ level of significance.

Table 1: Summary Statistics 


\begin{tabular}{llllllllll}
\hline & $c_{0, i}$ & $c_{1, i}$ & $\gamma_{i}$ & $\delta_{i}$ & $\phi_{i}$ & $\psi_{i}$ & $100 \omega_{i}$ & $\alpha_{i}$ & $\beta_{i}$ \\
\hline US & $0.165^{*}$ & -0.040 & & & & & 23.003 & $0.047 \sharp$ & $0.854^{*}$ \\
& $(0.055)$ & $(0.036)$ & & & & & $(18.238)$ & $(0.026)$ & $(0.091)$ \\
Eu & $0.141^{*}$ & 0.015 & 0.007 & & $0.086^{*}$ & & $0.888 \sharp$ & $0.069^{*}$ & $0.903^{*}$ \\
& $(0.019)$ & $(0.037)$ & $(0.013)$ & & $(0.018)$ & & $(0.493)$ & $(0.022)$ & $(0.031)$ \\
Be & $0.136^{*}$ & $-0.124^{*}$ & 0.008 & $0.127^{*}$ & $0.052^{*}$ & $0.863^{*}$ & 0.097 & $0.105 \S$ & $0.895^{*}$ \\
& $(0.014)$ & $(0.045)$ & $(0.008)$ & $(0.047)$ & $(0.011)$ & $(0.041)$ & $(0.114)$ & $(0.049)$ & $(0.049)$ \\
De & $0.144^{*}$ & -0.062 & 0.002 & $0.131^{*}$ & $0.057^{*}$ & $0.805^{*}$ & 0.213 & $0.157 \S$ & $0.843^{*}$ \\
& $(0.011)$ & $(0.052)$ & $(0.008)$ & $(0.048)$ & $(0.008)$ & $(0.028)$ & $(0.217)$ & $(0.075)$ & $(0.075)$ \\
Fr & $0.137^{*}$ & $-0.104 \S$ & 0.002 & $0.128^{*}$ & $0.042^{*}$ & $0.893^{*}$ & 0.386 & 0.241 & $0.759^{*}$ \\
& $(0.013)$ & $(0.043)$ & $(0.009)$ & $(0.046)$ & $(0.009)$ & $(0.045)$ & $(0.503)$ & $(0.148)$ & $(0.148)$ \\
Ge & $0.111^{*}$ & 0.037 & $0.019 \sharp$ & -0.001 & $0.028 \S$ & $0.568^{*}$ & 0.290 & $0.125 \sharp$ & $0.868^{*}$ \\
& $(0.014)$ & $(0.040)$ & $(0.010)$ & $(0.035)$ & $(0.012)$ & $(0.074)$ & $(0.284)$ & $(0.069)$ & $(0.063)$ \\
It & $0.161^{*}$ & -0.036 & 0.003 & 0.029 & $0.066^{*}$ & $0.933^{*}$ & 0.103 & $0.151^{*}$ & $0.849^{*}$ \\
& $(0.011)$ & $(0.051$ & $(0.009)$ & $(0.050)$ & $(0.009)$ & $(0.026)$ & $(0.739)$ & $(0.042)$ & $(0.042)$ \\
Ne & $0.119^{*}$ & $-0.108 \sharp$ & $0.013 \sharp$ & $0.125 \sharp$ & $0.046^{*}$ & $0.902^{*}$ & 0.079 & $0.120^{*}$ & $0.880^{*}$ \\
& $(0.018)$ & $(0.061)$ & $(0.008)$ & $(0.066)$ & $(0.014)$ & $(0.038)$ & $(0.072)$ & $(0.031)$ & $(0.031)$ \\
Sp & $0.151^{*}$ & $-0.122 \S$ & -0.003 & $0.147^{*}$ & $0.047^{*}$ & $0.992^{*}$ & 0.080 & $0.130^{*}$ & $0.870^{*}$ \\
& $(0.010)$ & $(0.052)$ & $(0.009)$ & $(0.057)$ & $(0.006)$ & $(0.022)$ & $(0.064)$ & $(0.039)$ & $(0.039)$ \\
Sw & $0.183^{*}$ & -0.063 & 0.016 & 0.060 & $0.266^{*}$ & $1.071^{*}$ & $2.405 \sharp$ & $0.103^{*}$ & $0.882^{*}$ \\
& $(0.033)$ & $(0.042)$ & $(0.027)$ & $(0.092)$ & $(0.023)$ & $(0.087)$ & $1.305)$ & $(0.025)$ & $(0.028)$ \\
UK & $0.182^{*}$ & -0.021 & -0.022 & 0.031 & $0.413^{*}$ & $0.721^{*}$ & 2.098 & 0.036 & $0.946^{*}$ \\
& $(0.039)$ & $(0.040)$ & $(0.034)$ & $(0.072)$ & $(0.052)$ & $(0.092)$ & $(3.283)$ & $(0.029)$ & $(0.052)$
\end{tabular}

The table reports the results from estimating the constant spillover model. US return: $R_{U S, t}=c_{0, U S}+c_{1, U S} R_{U S, t-1}+e_{U S, t}$ where $e_{U S, t}$ has mean 0 and conditional variance: $\sigma_{U S, t}^{2}=\omega_{U S}+\alpha_{U S} e_{U S, t-1}^{2}+\beta_{U S} \sigma_{U S, t-1}^{2}$. European return: $R_{E, t}=c_{0, E}+c_{1, E} R_{E, t-1}+$ $\gamma_{E} R_{U S, t-1}+\phi_{E} e_{U S, t}+e_{E, t}$ where $e_{E, t}$ has mean 0 and conditional variance: $\sigma_{E, t}^{2}=$ $\omega_{E}+\alpha_{E} e_{E, t-1}^{2}+\beta_{E} \sigma_{E, t-1}^{2}$. Country $i$ return (the European index excluding country $i$ is applied): $R_{i, t}=c_{0, i}+c_{1, i} R_{i, t-1}+\gamma_{i} R_{U S, t-1}+\delta_{i} R_{E, t-1}+\phi_{i} e_{U S, t}+\psi_{i} e_{E, t}+e_{i, t}$ where $e_{i, t}$ has mean 0 and conditional variance: $\sigma_{i, t}^{2}=\omega_{i}+\alpha_{i} e_{i, t-1}^{2}+\beta_{i} \sigma_{i, t-1}^{2}$. Bollerslev and Wooldridge (1992) robust standard errors in parentheses. * $(\S)[\#$, indicates that the value is significant at a $1 \%(5 \%)[10 \%]$ level of significance.

Table 2: Constant Spillover Model 


\begin{tabular}{llllll}
\hline & Wald $_{1}$ & Wald $_{2}$ & Wald $_{3}$ & Wald $_{4}$ & Wald $_{5}$ \\
\hline $\mathrm{Be}$ & $16.08^{*}$ & $621.61^{*}$ & $25.26^{*}$ & $450.51^{*}$ & $628.20^{*}$ \\
$\mathrm{De}$ & $11.15^{*}$ & $886.32^{*}$ & $50.42^{*}$ & $882.03^{*}$ & $955.42^{*}$ \\
$\mathrm{Fr}$ & $11.81^{*}$ & $541.92^{*}$ & $21.42^{*}$ & $425.30^{*}$ & $570.68^{*}$ \\
$\mathrm{Ge}$ & 4.03 & $67.93^{*}$ & $7.18 \S$ & $60.18^{*}$ & $70.19^{*}$ \\
$\mathrm{It}$ & 0.97 & $1444.46^{*}$ & $55.71^{*}$ & $13332.95^{*}$ & $1451.69^{*}$ \\
$\mathrm{Ne}$ & $8.09 \S$ & $644.69^{*}$ & $10.99^{*}$ & $580.89^{*}$ & $648.55^{*}$ \\
$\mathrm{Sp}$ & $10.98^{*}$ & $2223.67^{*}$ & $56.78^{*}$ & $2120.47^{*}$ & $2241.59^{*}$ \\
$\mathrm{Sw}$ & 1.18 & $325.53^{*}$ & $133.09^{*}$ & $161.50^{*}$ & $345.43^{*}$ \\
$\mathrm{UK}$ & 0.51 & $260.41^{*}$ & $65.55^{*}$ & $62.15^{*}$ & $262.14^{*}$
\end{tabular}

The table reports the joint robust Wald tests for the following null hypotheses regarding the spillover effects in the constant spillover model:

$\mathrm{H}_{0}^{1}: \gamma_{i}=\delta_{i}=0$ (no mean-spillover effects).

$\mathrm{H}_{0}^{2}: \phi_{i}=\psi_{i}=0$ (no volatility-spillover effects).

$\mathrm{H}_{0}^{3}: \gamma_{i}=\phi_{i}=0$ (no US-spillover effects).

$\mathrm{H}_{0}^{4}: \delta_{i}=\psi_{i}=0$ (no European-spillover effects).

$\mathrm{H}_{o}^{5}: \gamma_{i}=\delta_{i}=\phi_{i}=\psi_{i}=0$ (no spillover effects).

Under the null hypotheses Wald $_{1}$, Wald $_{2}$, Wald 3 , and Wald 4 are $\chi^{2}(2)$ distributed and Wald $_{5}$ is $\chi^{2}(4)$ distributed. ${ }^{*}(\S)[H]$, indicates that the test statistic is significant at a $1 \%$ $(5 \%)[10 \%]$ level of significance.

Table 3: Tests for Spillover Effects - Constant Spillover Model 


\begin{tabular}{lllllll}
\hline & \multicolumn{2}{c}{$V R_{i, t}^{U S}$} & \multicolumn{2}{c}{$V R_{i, t}^{E}$} & \multicolumn{2}{c}{$V R_{i, t}^{i}$} \\
& Mean & Stdev. & Mean & Stdev. & Mean & Stdev. \\
\hline $\mathrm{Be}$ & 0.019 & 0.011 & 0.605 & 0.172 & 0.375 & 0.178 \\
$\mathrm{De}$ & 0.024 & 0.014 & 0.551 & 0.192 & 0.425 & 0.200 \\
$\mathrm{Fr}$ & 0.012 & 0.006 & 0.615 & 0.178 & 0.373 & 0.181 \\
$\mathrm{Ge}$ & 0.008 & 0.005 & 0.459 & 0.118 & 0.532 & 0.119 \\
$\mathrm{It}$ & 0.022 & 0.016 & 0.441 & 0.281 & 0.536 & 0.295 \\
$\mathrm{Ne}$ & 0.015 & 0.008 & 0.653 & 0.170 & 0.332 & 0.175 \\
$\mathrm{Sp}$ & 0.011 & 0.008 & 0.544 & 0.259 & 0.445 & 0.265 \\
$\mathrm{Sw}$ & 0.119 & 0.060 & 0.221 & 0.077 & 0.659 & 0.113 \\
$\mathrm{UK}$ & 0.231 & 0.047 & 0.100 & 0.066 & 0.668 & 0.082
\end{tabular}

The table reports the mean and standard deviation of the US, European, and own variance ratios for the constant spillover model: $V R_{i, t}^{U S}=\frac{\phi_{i}^{2} \sigma_{U S, t}^{2}}{h_{i, t}}, V R_{i, t}^{E}=\frac{\psi_{i}^{2} \sigma_{E, t}^{2}}{h_{i, t}}$, and $V R_{i, t}^{i}=1-$ $V R_{i, t}^{U S}-V R_{i, t}^{E}$. $\sigma_{U S, t}\left(\sigma_{E, t}\right)$ is the conditional volatility of the US (European) idiosyncratic shock and $h_{i, t}$ is the conditional variance of the unexpected return of country $i$.

Table 4: Variance Ratios - Constant Spillover Model 


\begin{tabular}{|c|c|c|c|c|c|c|c|c|c|c|}
\hline & $c_{0, i}$ & $c_{1, i}$ & $\gamma_{0, i}$ & $\gamma_{1, i}$ & $\delta_{0, i}$ & $\delta_{1, i}$ & $\phi_{0, i}$ & $\phi_{1, i}$ & $\psi_{0, i}$ & $\psi_{1, i}$ \\
\hline US & $\begin{array}{l}0.165^{*} \\
(0.055)\end{array}$ & $\begin{array}{l}-0.040 \\
(0.036)\end{array}$ & & & & & & & & \\
\hline Eu & $\begin{array}{l}0.145^{*} \\
(0.019)\end{array}$ & $\begin{array}{l}0.009 \\
(0.038)\end{array}$ & $\begin{array}{l}0.013 \\
(0.016)\end{array}$ & $\begin{array}{l}-0.020 \\
(0.025)\end{array}$ & & & $\begin{array}{l}0.105^{*} \\
(0.023)\end{array}$ & $\begin{array}{c}-0.077 \S \\
(0.031)\end{array}$ & & \\
\hline $\mathrm{Be}$ & $\begin{array}{l}0.150^{*} \\
(0.011)\end{array}$ & $\begin{array}{c}-0.147^{*} \\
(0.047)\end{array}$ & $\begin{array}{l}0.018 \\
(0.016)\end{array}$ & $\begin{array}{r}-0.033 \S \\
(0.016)\end{array}$ & $\begin{array}{l}0.092 \sharp \\
(0.052)\end{array}$ & $\begin{array}{l}0.083 \S \\
(0.042)\end{array}$ & $\begin{array}{l}0.075^{*} \\
(0.023)\end{array}$ & $\begin{array}{c}-0.042 \sharp \\
(0.024)\end{array}$ & $\begin{array}{l}0.556^{*} \\
(0.055)\end{array}$ & $\begin{array}{l}0.466^{*} \\
(0.058)\end{array}$ \\
\hline De & $\begin{array}{l}0.145^{*} \\
(0.011)\end{array}$ & $\begin{array}{l}-0.059 \\
(0.053)\end{array}$ & $\begin{array}{c}-0.003 \\
(0.013)\end{array}$ & $\begin{array}{l}0.002 \\
(0.015)\end{array}$ & $\begin{array}{l}0.138 \S \\
(0.058)\end{array}$ & $\begin{array}{c}-0.025 \\
(0.041)\end{array}$ & $\begin{array}{l}0.080^{*} \\
(0.015)\end{array}$ & $\begin{array}{c}-0.048^{*} \\
(0.017)\end{array}$ & $\begin{array}{l}0.782^{*} \\
(0.059)\end{array}$ & $\begin{array}{l}0.038 \\
(0.064)\end{array}$ \\
\hline $\mathrm{Fr}$ & $\begin{array}{l}0.144^{*} \\
(0.011)\end{array}$ & $\begin{array}{c}-0.088 \S \\
(0.041)\end{array}$ & $\begin{array}{l}0.013 \\
(0.018)\end{array}$ & $\begin{array}{l}-0.023 \\
(0.020)\end{array}$ & $\begin{array}{l}0.101 \S \\
(0.051)\end{array}$ & $\begin{array}{l}0.022 \\
(0.043)\end{array}$ & $\begin{array}{l}0.076^{*} \\
(0.017)\end{array}$ & $\begin{array}{r}-0.039 \S \\
(0.018)\end{array}$ & $\begin{array}{l}0.693^{*} \\
(0.063)\end{array}$ & $\begin{array}{l}0.352^{*} \\
(0.068)\end{array}$ \\
\hline $\mathrm{Ge}$ & $\begin{array}{l}0.135^{*} \\
(0.009)\end{array}$ & $\begin{array}{l}-0.005 \\
(0.046)\end{array}$ & $\begin{array}{l}0.032 \sharp \\
(0.019)\end{array}$ & $\begin{array}{l}-0.031 \\
(0.021)\end{array}$ & $\begin{array}{l}-0.014 \\
(0.037)\end{array}$ & $\begin{array}{l}0.040 \\
(0.043)\end{array}$ & $\begin{array}{l}0.037 \sharp \\
(0.022)\end{array}$ & $\begin{array}{l}0.000 \\
(0.023)\end{array}$ & $\begin{array}{l}0.365^{*} \\
(0.054)\end{array}$ & $\begin{array}{l}0.627^{*} \\
(0.057)\end{array}$ \\
\hline It & $\begin{array}{l}0.167^{*} \\
(0.011)\end{array}$ & $\begin{array}{l}-0.033 \\
(0.053)\end{array}$ & $\begin{array}{l}0.008 \\
(0.028)\end{array}$ & $\begin{array}{l}-0.015 \\
(0.028)\end{array}$ & $\begin{array}{l}-0.018 \\
(0.086)\end{array}$ & $\begin{array}{l}0.054 \\
(0.077)\end{array}$ & $\begin{array}{l}0.136^{*} \\
(0.030)\end{array}$ & $\begin{array}{c}-0.103^{*} \\
(0.031)\end{array}$ & $\begin{array}{l}0.732^{*} \\
(0.116)\end{array}$ & $\begin{array}{c}0.242 \S \\
(0.119)\end{array}$ \\
\hline $\mathrm{Ne}$ & $\begin{array}{l}0.128^{*} \\
(0.009)\end{array}$ & $\begin{array}{l}-0.121 \S \\
(0.060)\end{array}$ & $\begin{array}{l}0.028 \\
(0.026)\end{array}$ & $\begin{array}{l}-0.033 \\
(0.028)\end{array}$ & $\begin{array}{l}0.097 \\
(0.061)\end{array}$ & $\begin{array}{l}0.049 \\
(0.055)\end{array}$ & $\begin{array}{l}0.078 \\
(0.051)\end{array}$ & $\begin{array}{l}-0.048 \\
(0.051)\end{array}$ & $\begin{array}{l}0.578^{*} \\
(0.089)\end{array}$ & $\begin{array}{l}0.446^{*} \\
(0.090)\end{array}$ \\
\hline $\mathrm{Sp}$ & $\begin{array}{l}0.151^{*} \\
(0.010)\end{array}$ & $\begin{array}{l}-0.107 \S \\
(0.052)\end{array}$ & $\begin{array}{l}-0.016 \\
(0.025)\end{array}$ & $\begin{array}{l}0.004 \\
(0.025)\end{array}$ & $\begin{array}{l}0.165 \S \\
(0.075)\end{array}$ & $\begin{array}{l}-0.039 \\
(0.061)\end{array}$ & $\begin{array}{l}0.092^{*} \\
(0.020)\end{array}$ & $\begin{array}{c}-0.060^{*} \\
(0.021)\end{array}$ & $\begin{array}{l}0.923^{*} \\
(0.057)\end{array}$ & $\begin{array}{l}0.089 \\
(0.061)\end{array}$ \\
\hline $\mathrm{Sw}$ & $\begin{array}{l}0.172^{*} \\
(0.036)\end{array}$ & $\begin{array}{l}-0.051 \\
(0.041)\end{array}$ & $\begin{array}{l}0.021 \\
(0.030)\end{array}$ & $\begin{array}{l}-0.003 \\
(0.061)\end{array}$ & $\begin{array}{l}0.014 \\
(0.112)\end{array}$ & $\begin{array}{l}0.171 \\
(0.167)\end{array}$ & $\begin{array}{l}0.289^{*} \\
(0.026)\end{array}$ & $\begin{array}{l}-0.069 \\
(0.058)\end{array}$ & $\begin{array}{l}1.238^{*} \\
\left(0.107^{*}\right)\end{array}$ & $\begin{array}{c}-0.683^{*} \\
(0.170)\end{array}$ \\
\hline UK & $\begin{array}{l}0.177^{*} \\
(0.039)\end{array}$ & $\begin{array}{l}-0.007 \\
(0.040)\end{array}$ & $\begin{array}{l}0.000 \\
(0.040)\end{array}$ & $\begin{array}{r}-0.102 \sharp \\
(0.056)\end{array}$ & $\begin{array}{l}-0.012 \\
(0.091)\end{array}$ & $\begin{array}{l}0.155 \\
(0.134)\end{array}$ & $\begin{array}{l}0.318^{*} \\
(0.049)\end{array}$ & $\begin{array}{l}0.274^{*} \\
(0.063)\end{array}$ & $\begin{array}{l}0.843^{*} \\
(0.103)\end{array}$ & $\begin{array}{c}-0.323 \S \\
(0.162)\end{array}$ \\
\hline
\end{tabular}

The table reports the results from estimating the euro spillover model. US return: $R_{U S, t}=$ $c_{0, U S}+c_{1, U S} R_{U S, t-1}+e_{U S, t}$ where $e_{U S, t}$ has mean 0 and conditional variance: $\sigma_{U S, t}^{2}=$ $\omega_{U S}+\alpha_{U S} e_{U S, t-1}^{2}+\beta_{U S} \sigma_{U S, t-1}^{2}$. European return: $R_{E, t}=c_{0, E}+c_{1, E} R_{E, t-1}+\left(\gamma_{0, E}+\right.$ $\left.\gamma_{1, E} D_{t-1}\right) R_{U S, t-1}+\left(\phi_{0, E}+\phi_{1, E} D_{t-1}\right) e_{U S, t}+e_{E, t}$ where $e_{E, t}$ has mean 0 and conditional variance: $\sigma_{E, t}^{2}=\omega_{E}+\alpha_{E} e_{E, t-1}^{2}+\beta_{E} \sigma_{E, t-1}^{2}$. Country $i$ return (the European index excluding country $i$ is applied): $R_{i, t}=c_{0, i}+c_{1, i} R_{i, t-1}+\left(\gamma_{0, i}+\gamma_{1, i} D_{t-1}\right) R_{U S, t-1}+\left(\delta_{0, i}+\right.$ $\left.\delta_{1, i} D_{t-1}\right) R_{E, t-1}+\left(\phi_{0, i}+\phi_{1, i} D_{t-1}\right) e_{U S, t}+\left(\psi_{0, i}+\psi_{1, i} D_{t-1}\right) e_{E, t}+e_{i, t}$ where $e_{i, t}$ has mean 0 and conditional variance: $\sigma_{i, t}^{2}=\omega_{i}+\alpha_{i} e_{i, t-1}^{2}+\beta_{i} \sigma_{i, t-1}^{2}$. $D_{t}$ equals 0 before January 1, 1999 and 1 hereafter. $\hat{\omega}_{i}, \hat{\alpha}_{i}$, and $\hat{\beta}_{i}$ not reported. Bollerslev and Wooldridge (1992) robust standard errors in parentheses. ${ }^{*}(\S)[\#]$, indicates that the value is significant at a $1 \%(5 \%)[10 \%]$ level of significance.

Table 5: Euro Spillover Model 


\begin{tabular}{lllllll}
\hline & \multicolumn{2}{c}{$V R_{i, t}^{U S}$} & \multicolumn{2}{c}{$V R_{i, t}^{E}$} & \multicolumn{2}{c}{$V R_{i, t}^{i}$} \\
& Mean & Stdev. & Mean & Stdev. & Mean & Stdev. \\
\hline $\mathrm{Be}$ & 0.041 & 0.034 & 0.496 & 0.249 & 0.462 & 0.239 \\
$\mathrm{De}$ & 0.033 & 0.026 & 0.542 & 0.200 & 0.424 & 0.202 \\
$\mathrm{Fr}$ & 0.032 & 0.023 & 0.550 & 0.227 & 0.418 & 0.220 \\
$\mathrm{Ge}$ & 0.017 & 0.010 & 0.436 & 0.274 & 0.547 & 0.271 \\
$\mathrm{It}$ & 0.061 & 0.061 & 0.392 & 0.306 & 0.548 & 0.306 \\
$\mathrm{Ne}$ & 0.045 & 0.035 & 0.530 & 0.241 & 0.425 & 0.228 \\
$\mathrm{Sp}$ & 0.027 & 0.023 & 0.523 & 0.267 & 0.450 & 0.268 \\
$\mathrm{Sw}$ & 0.122 & 0.061 & 0.227 & 0.121 & 0.651 & 0.153 \\
$\mathrm{UK}$ & 0.223 & 0.140 & 0.120 & 0.096 & 0.670 & 0.124
\end{tabular}

The table reports the mean and standard deviation of the US, European, and own variance ratios for the euro spillover model: $V R_{i, t}^{U S}=\frac{\left(\phi_{0, i}+\phi_{1, i} D_{t-1}\right)^{2} \sigma_{U S, t}^{2}}{h_{i, t}}, V R_{i, t}^{E}=$ $\frac{\left(\psi_{0, i}+\psi_{1, i} D_{t-1}\right)^{2} \sigma_{E, t}^{2}}{h_{i, t}}$, and $V R_{i, t}^{i}=1-V R_{i, t}^{U S}-V R_{i, t}^{E} . \sigma_{U S, t}\left(\sigma_{E, t}\right)$ is the conditional volatility of the US (European) idiosyncratic shock and $h_{i, t}$ is the conditional variance of the unexpected return of country $i$. $D_{t}$ equals 0 before January 1,1999 and 1 hereafter.

Table 6: Variance Ratios - Euro Spillover Model 


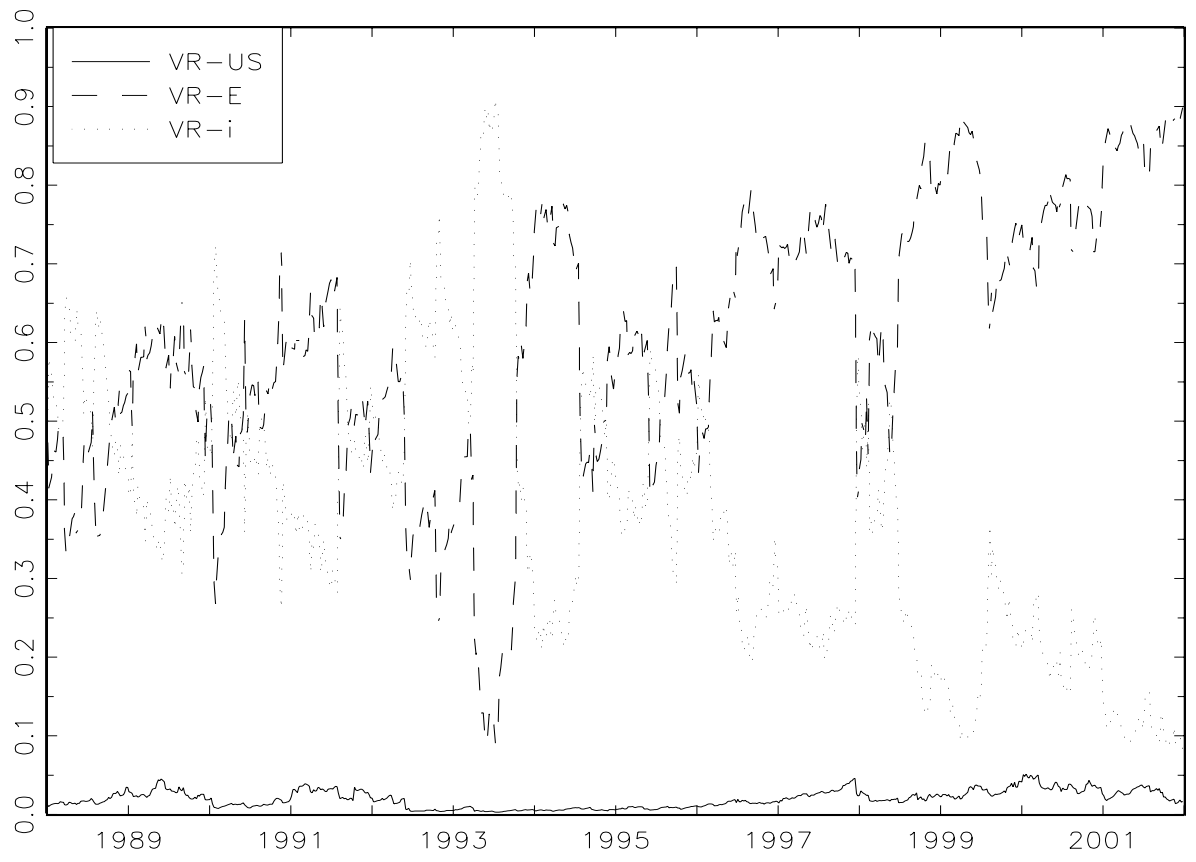

Figure 1: Variance Ratios - Belgium - Constant Spillover Model

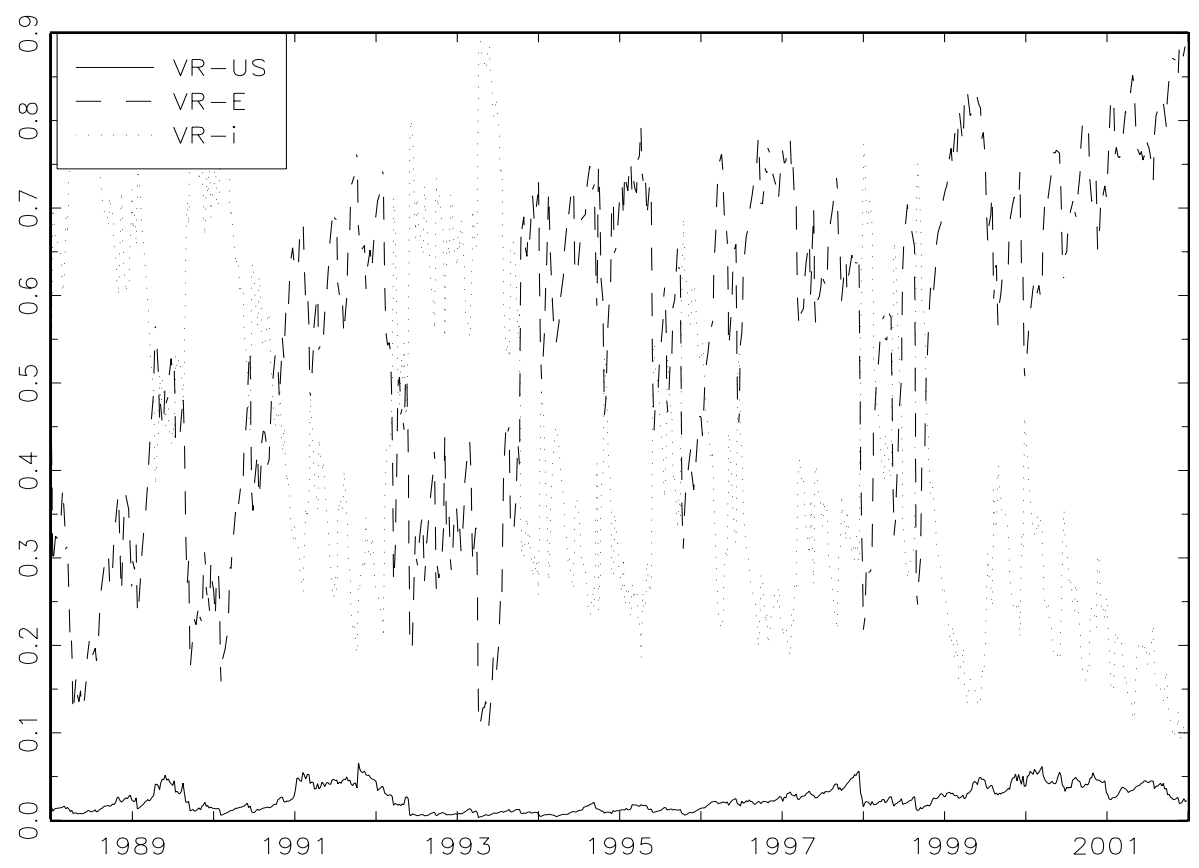

Figure 2: Variance Ratios - Denmark - Constant Spillover Model 


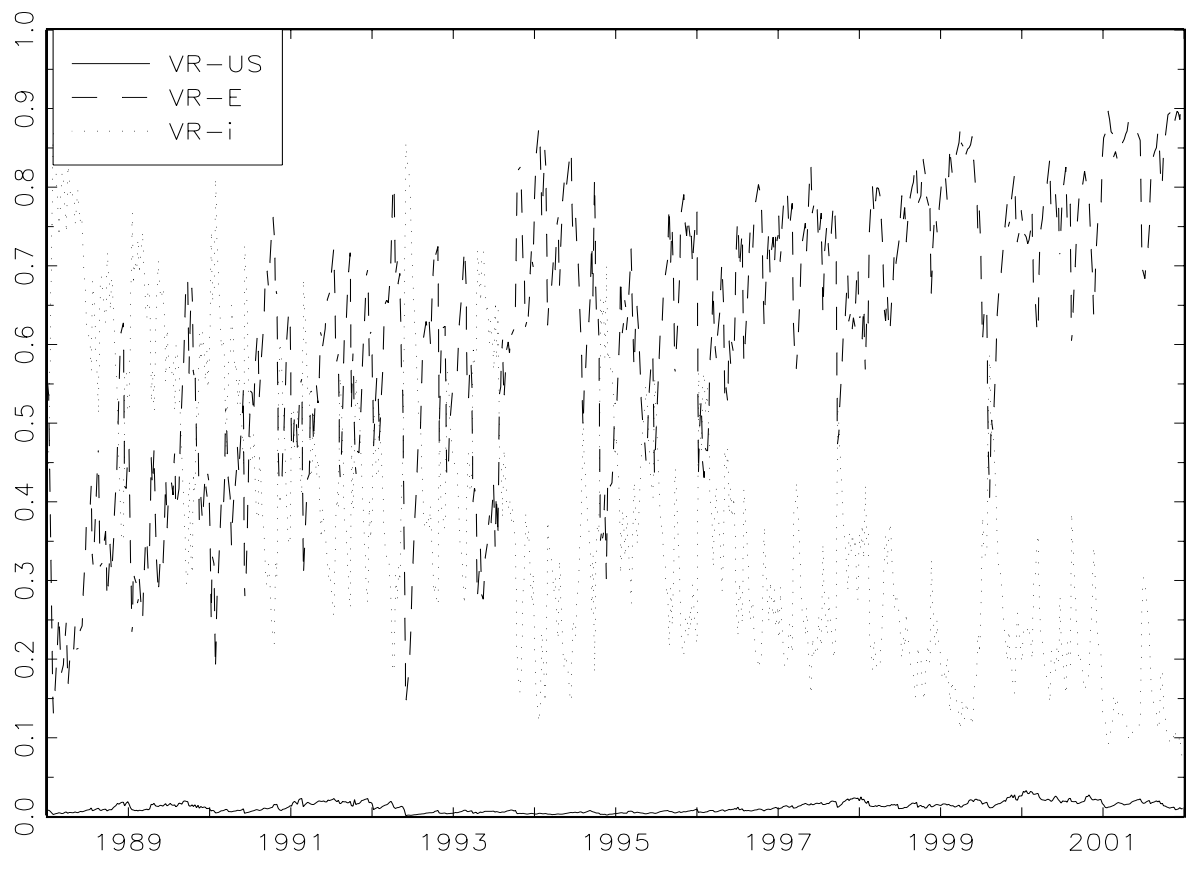

Figure 3: Variance Ratios - France - Constant Spillover Model

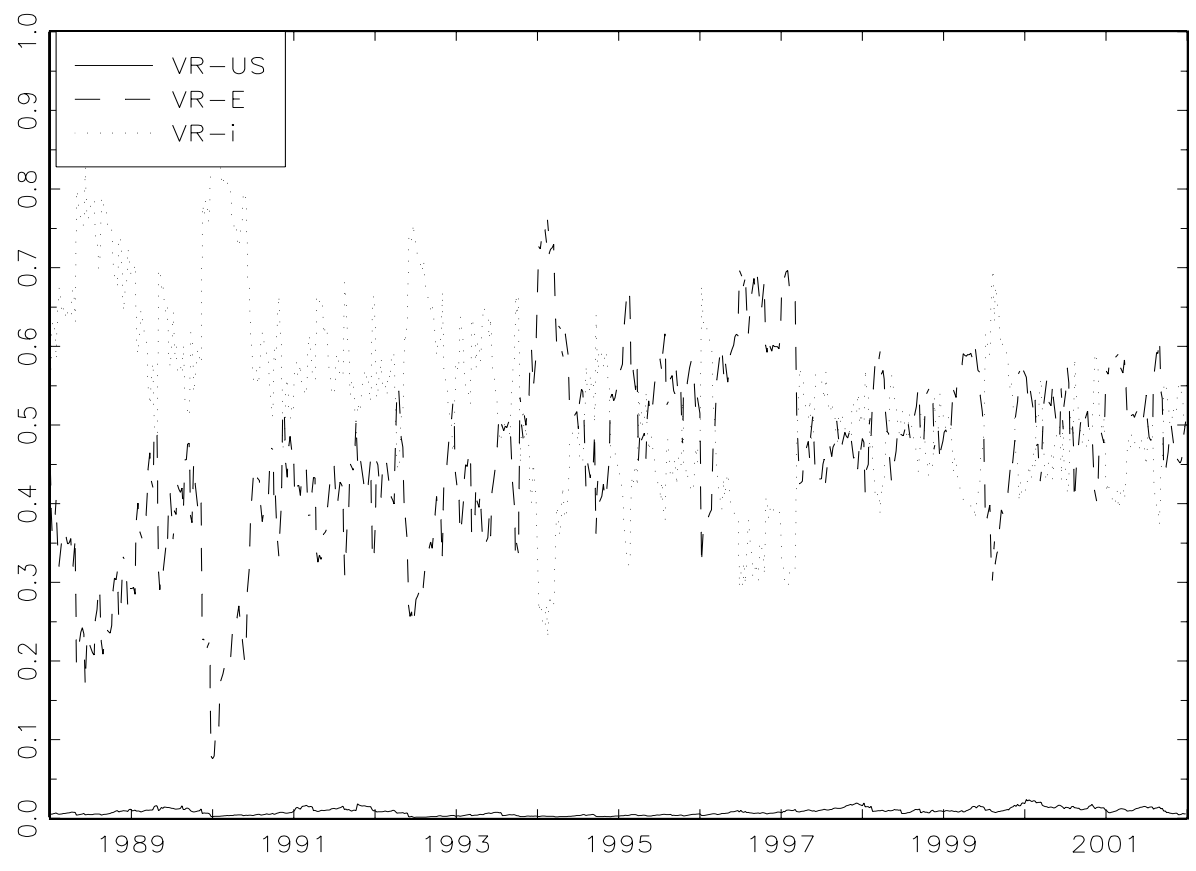

Figure 4: Variance Ratios - Germany - Constant Spillover Model 


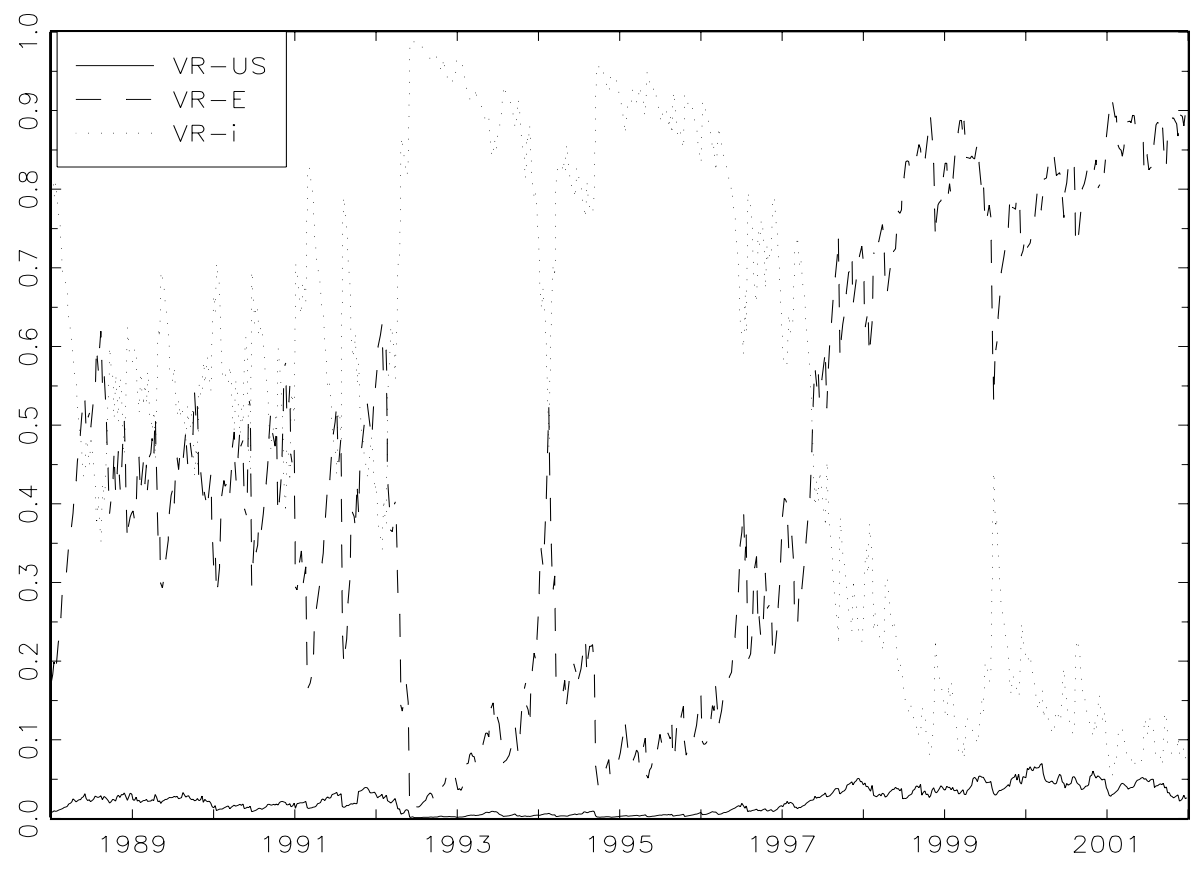

Figure 5: Variance Ratios - Italy - Constant Spillover Model

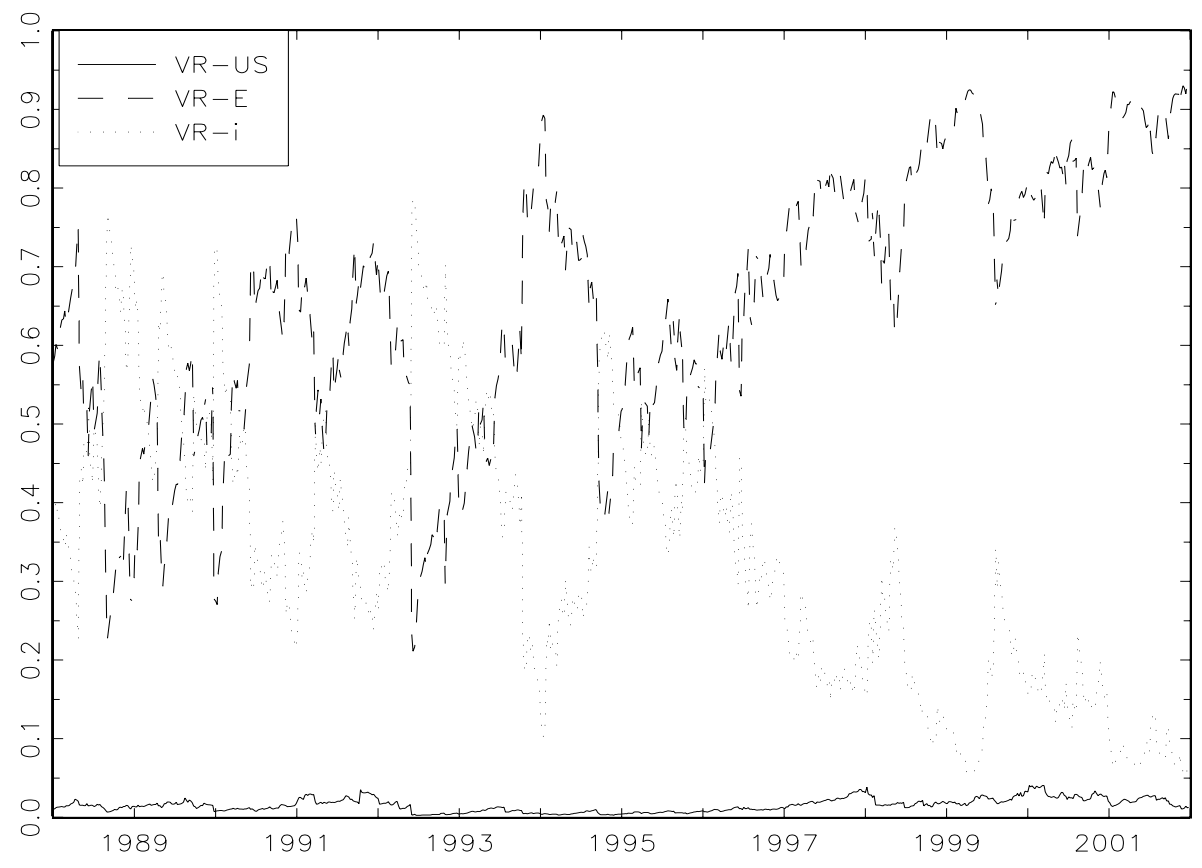

Figure 6: Variance Ratios - Netherlands - Constant Spillover Model 


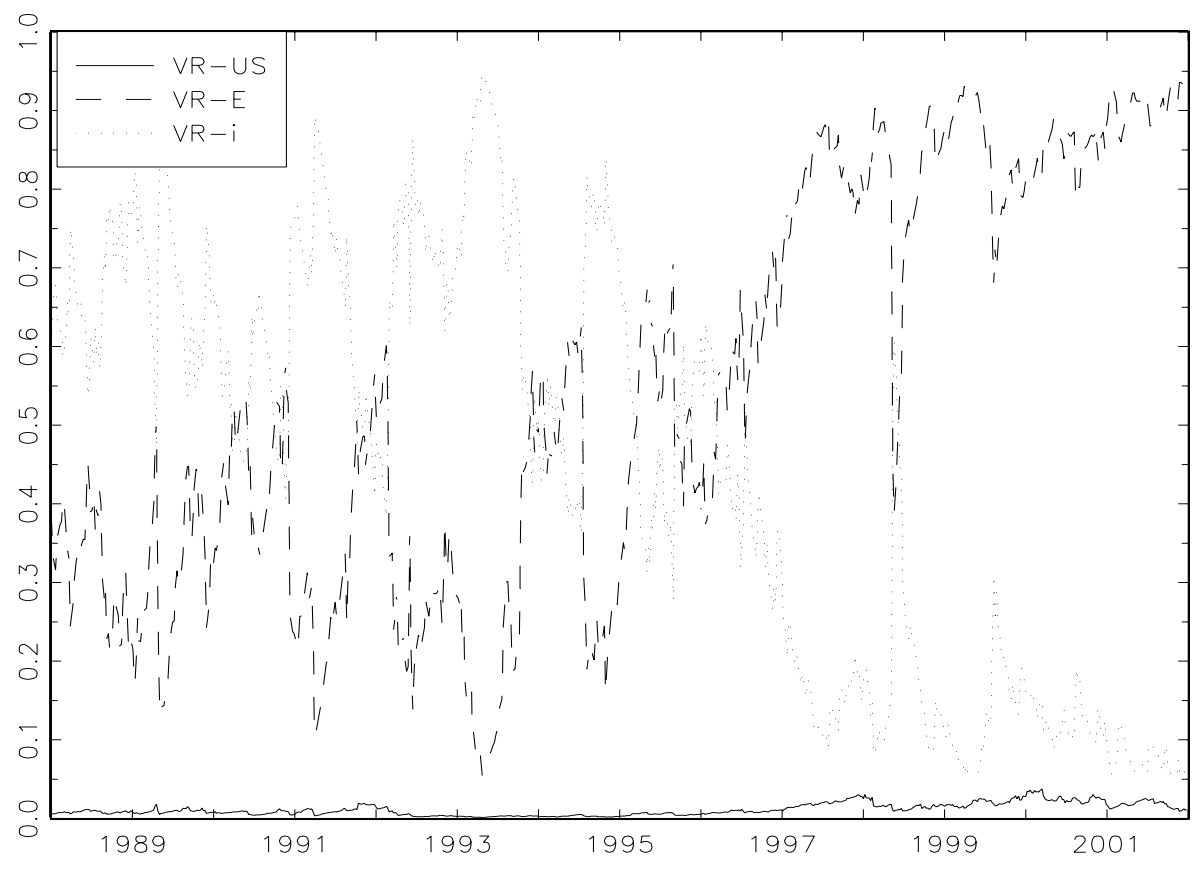

Figure 7: Variance Ratios - Spain - Constant Spillover Model

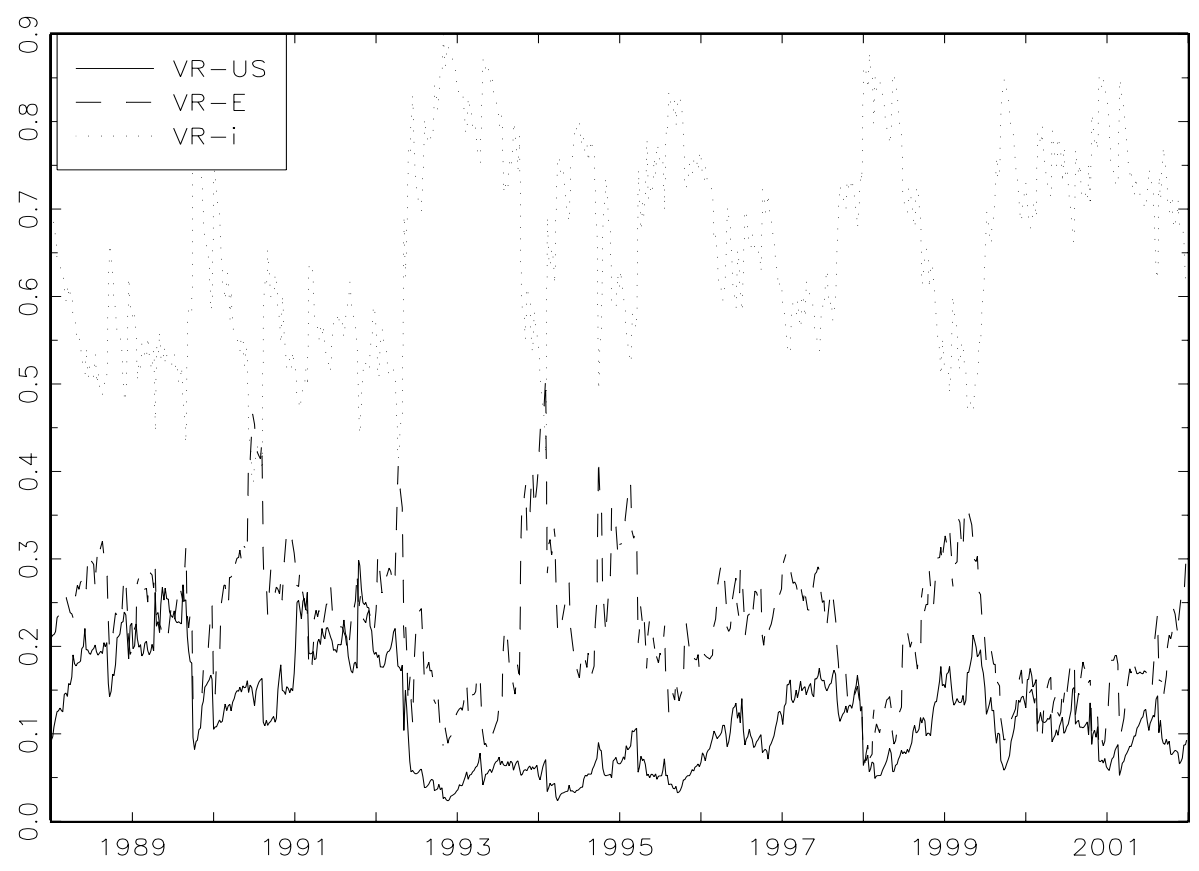

Figure 8: Variance Ratios - Sweden - Constant Spillover Model 


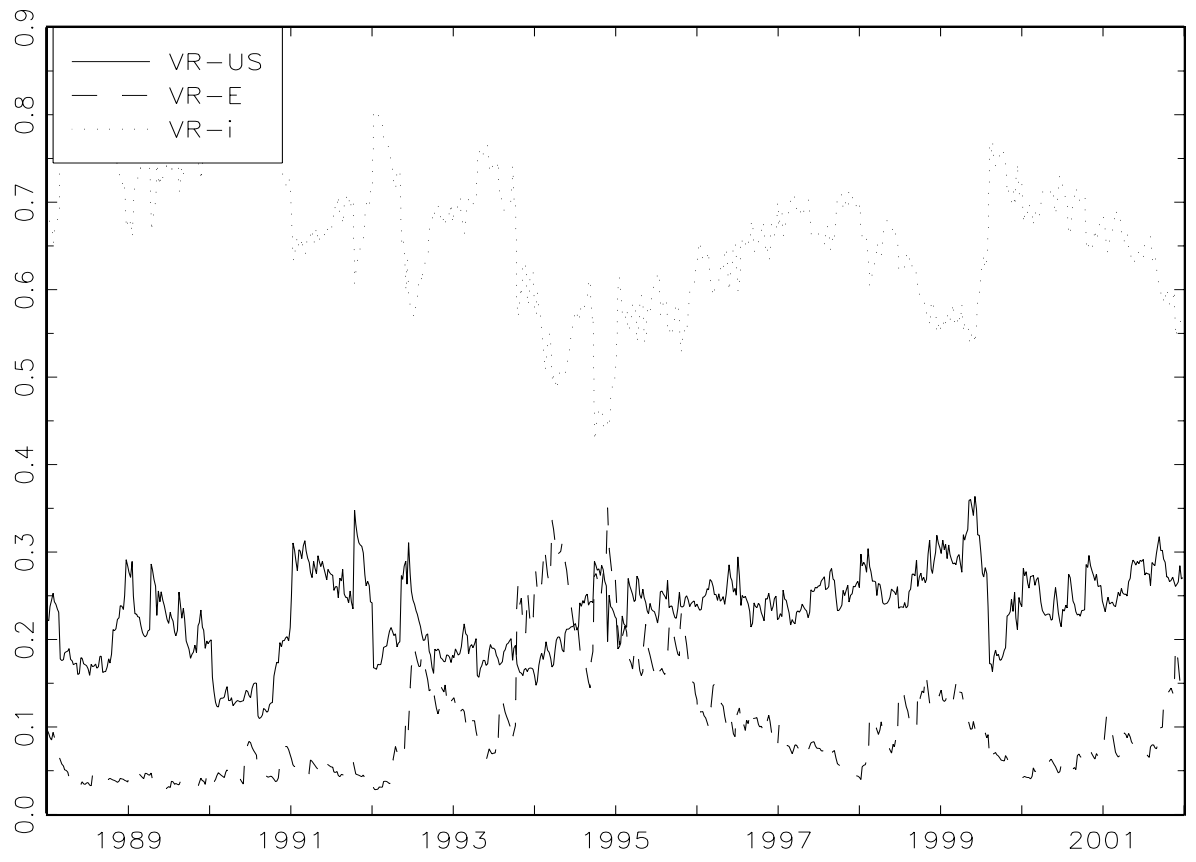

Figure 9: Variance Ratios - United Kingdom - Constant Spillover Model

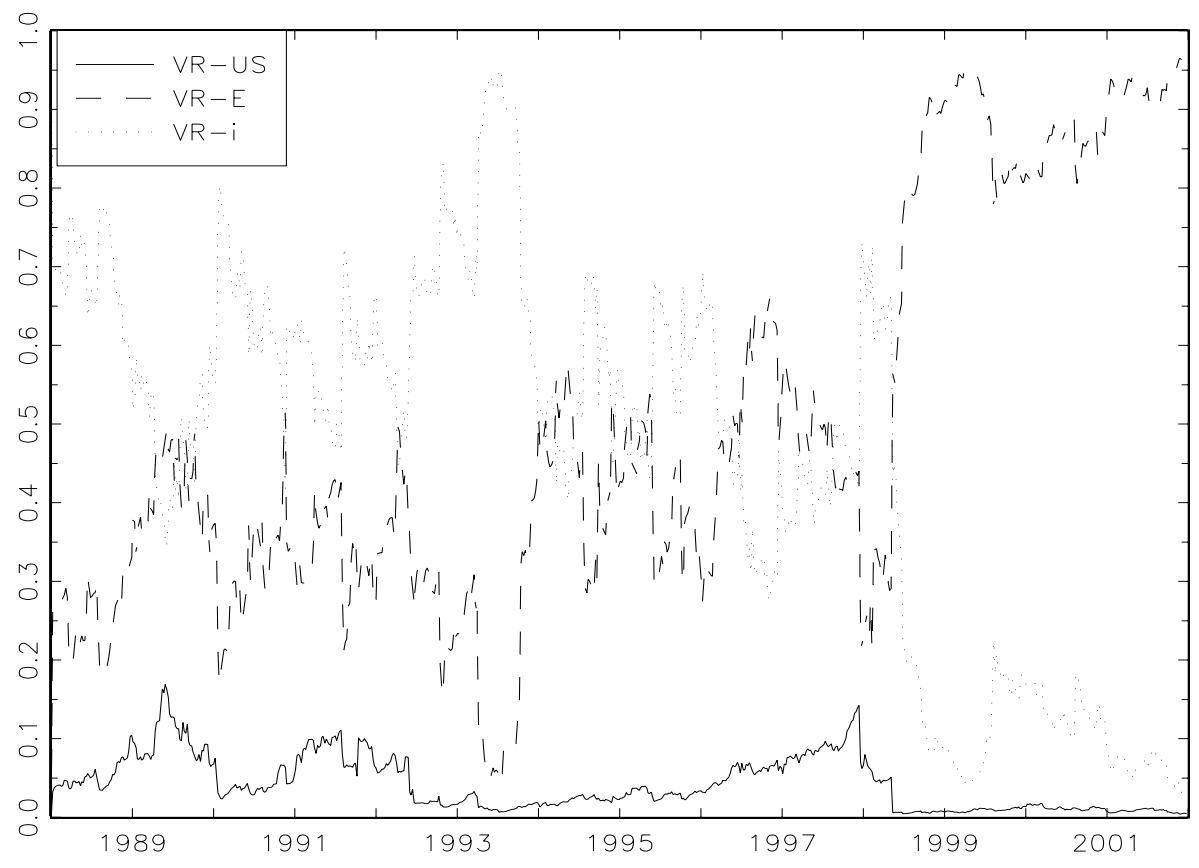

Figure 10: Variance Ratios - Belgium - Euro Spillover Model 


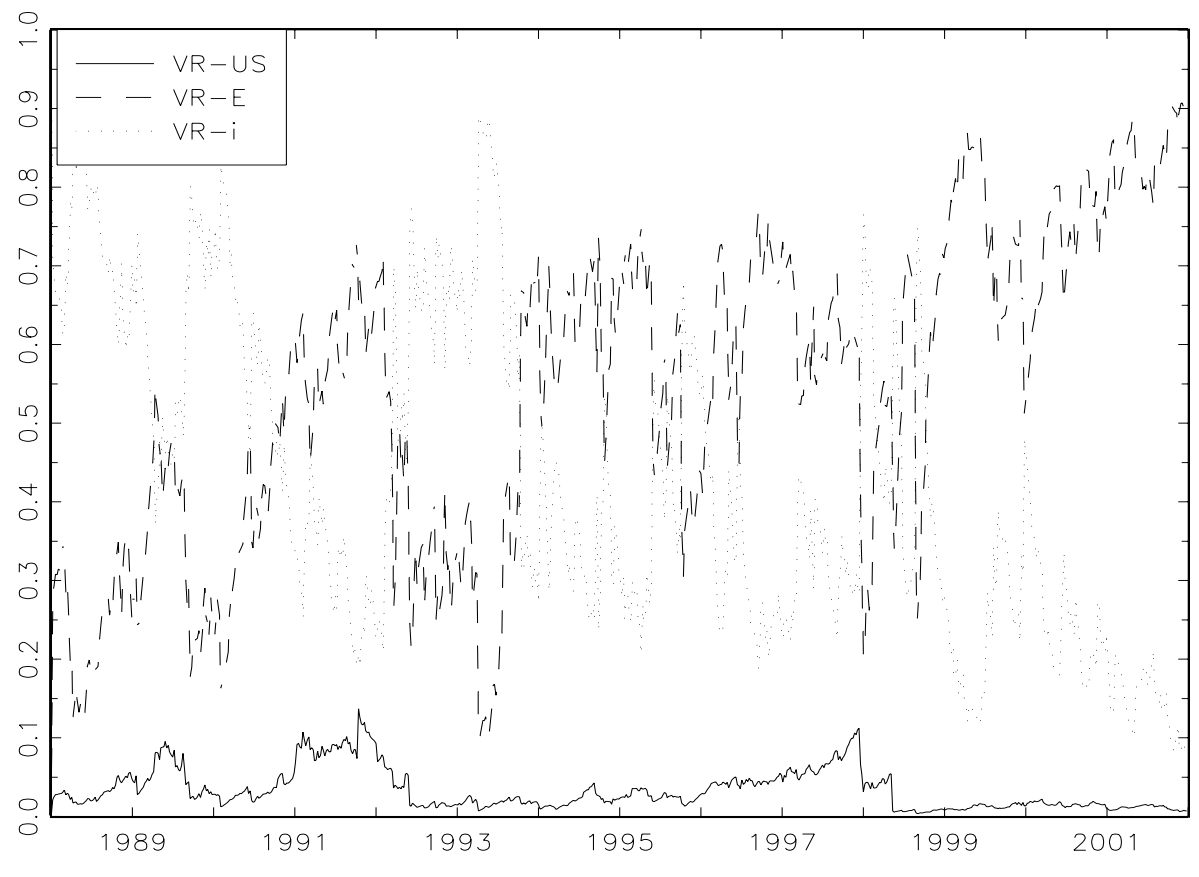

Figure 11: Variance Ratios - Denmark - Euro Spillover Model

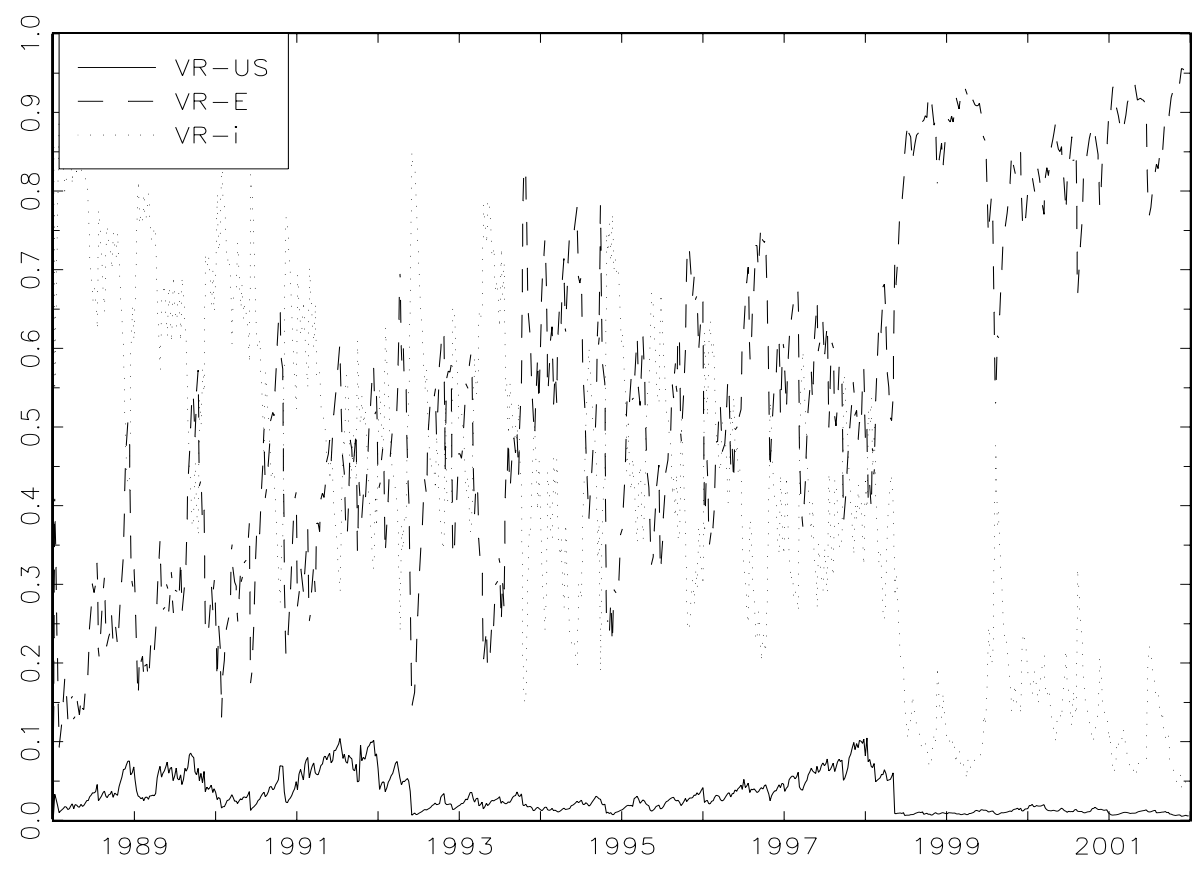

Figure 12: Variance Ratios - France - Euro Spillover Model 


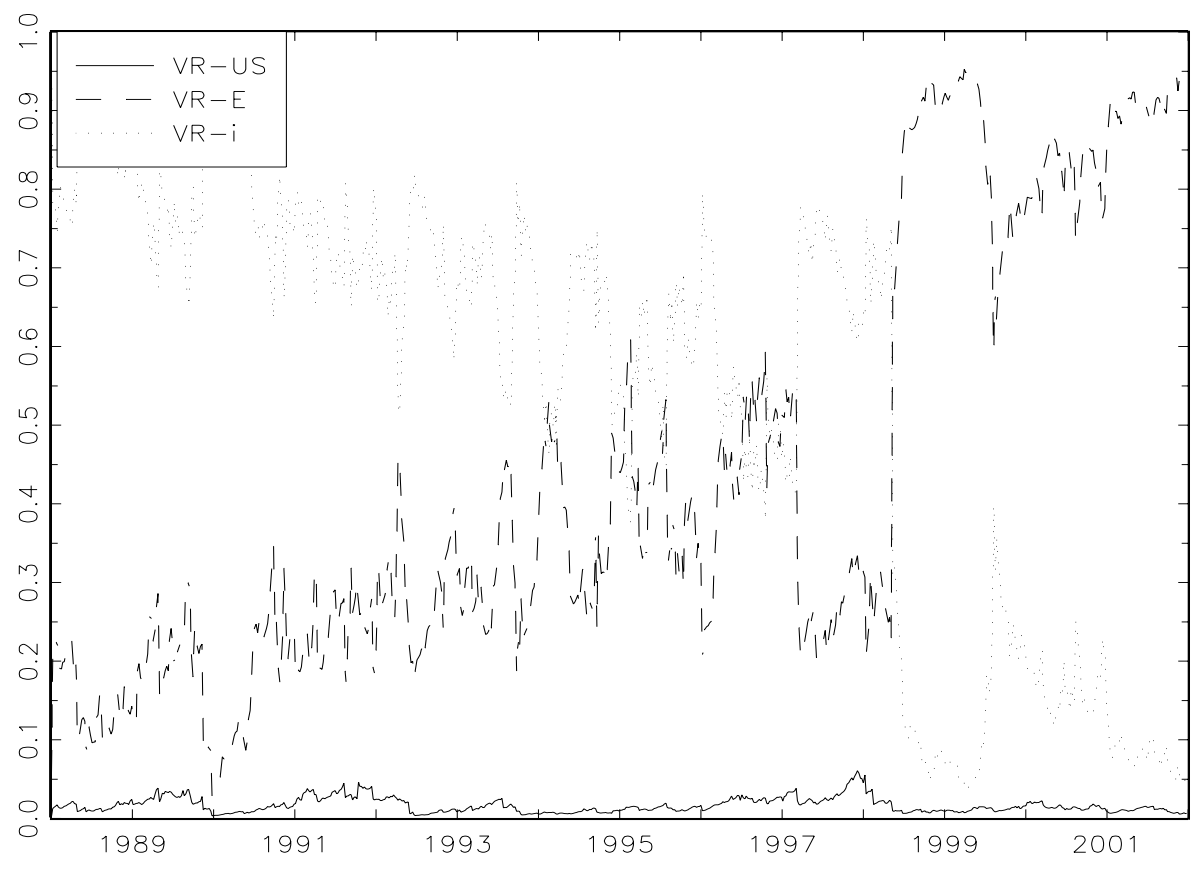

Figure 13: Variance Ratios - Germany - Euro Spillover Model

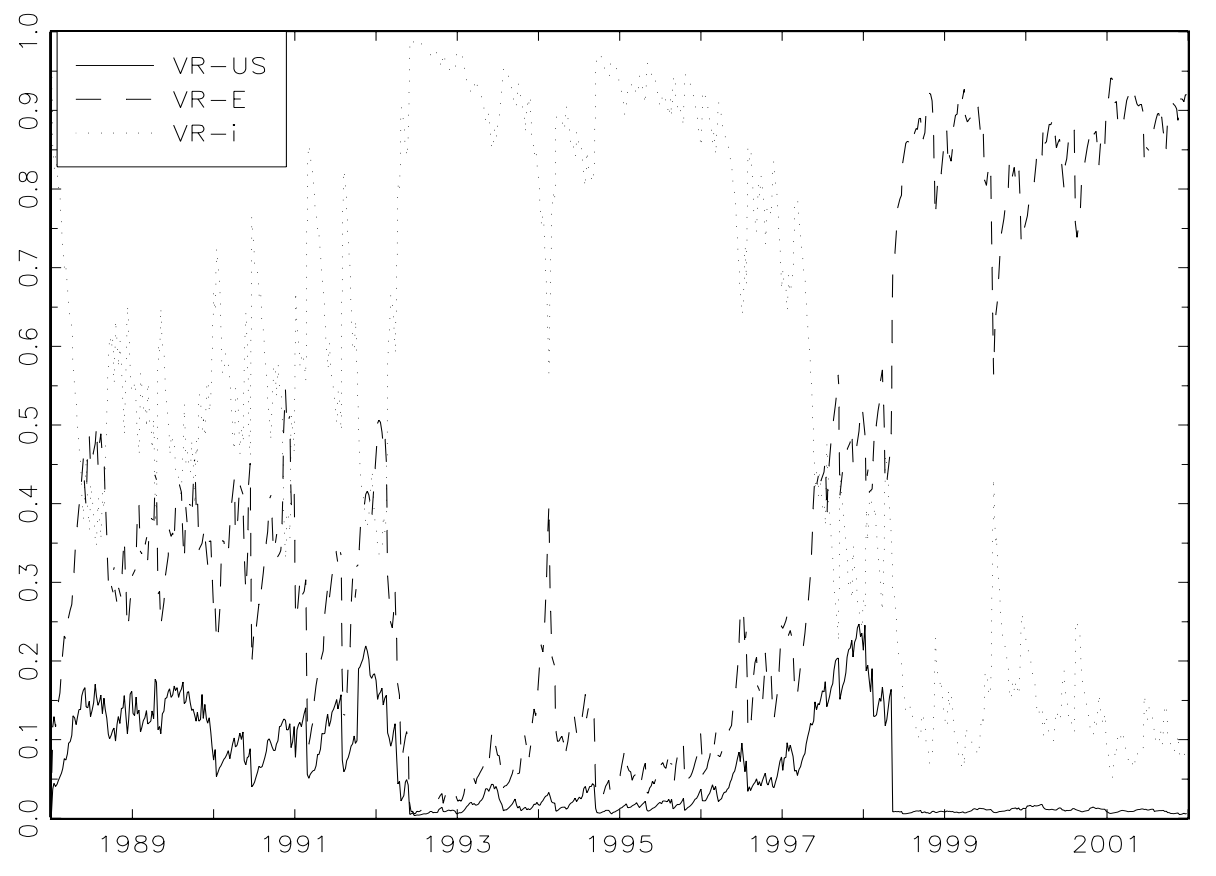

Figure 14: Variance Ratios - Italy - Euro Spillover Model 


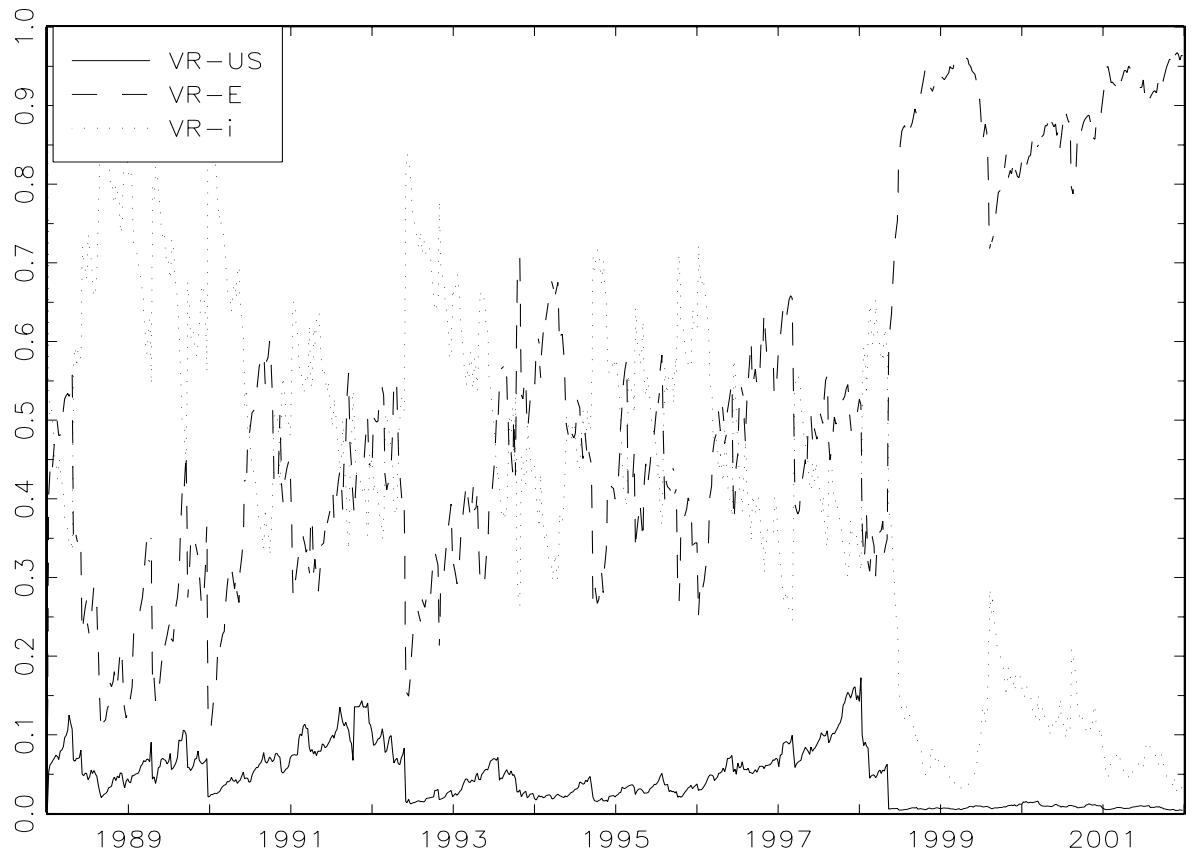

Figure 15: Variance Ratios - Netherlands - Euro Spillover Model

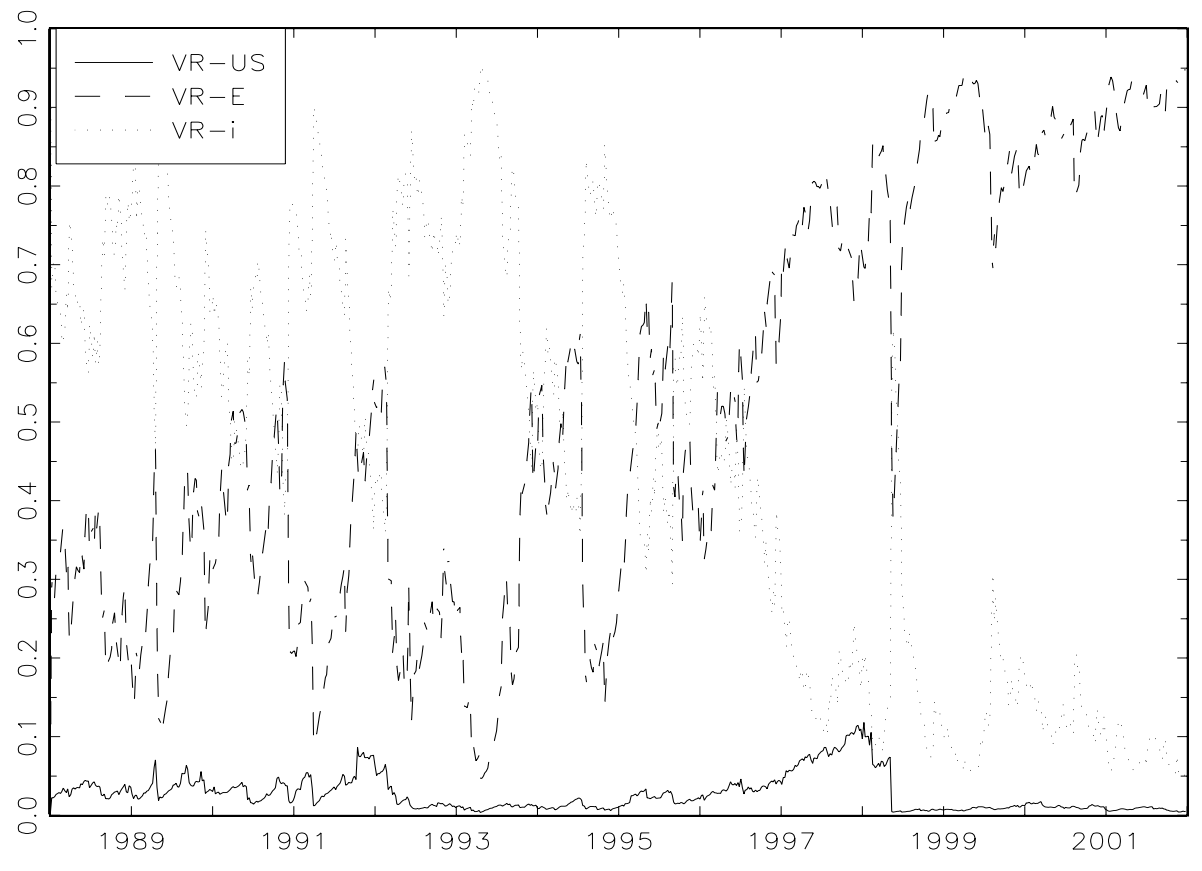

Figure 16: Variance Ratios - Spain - Euro Spillover Model 


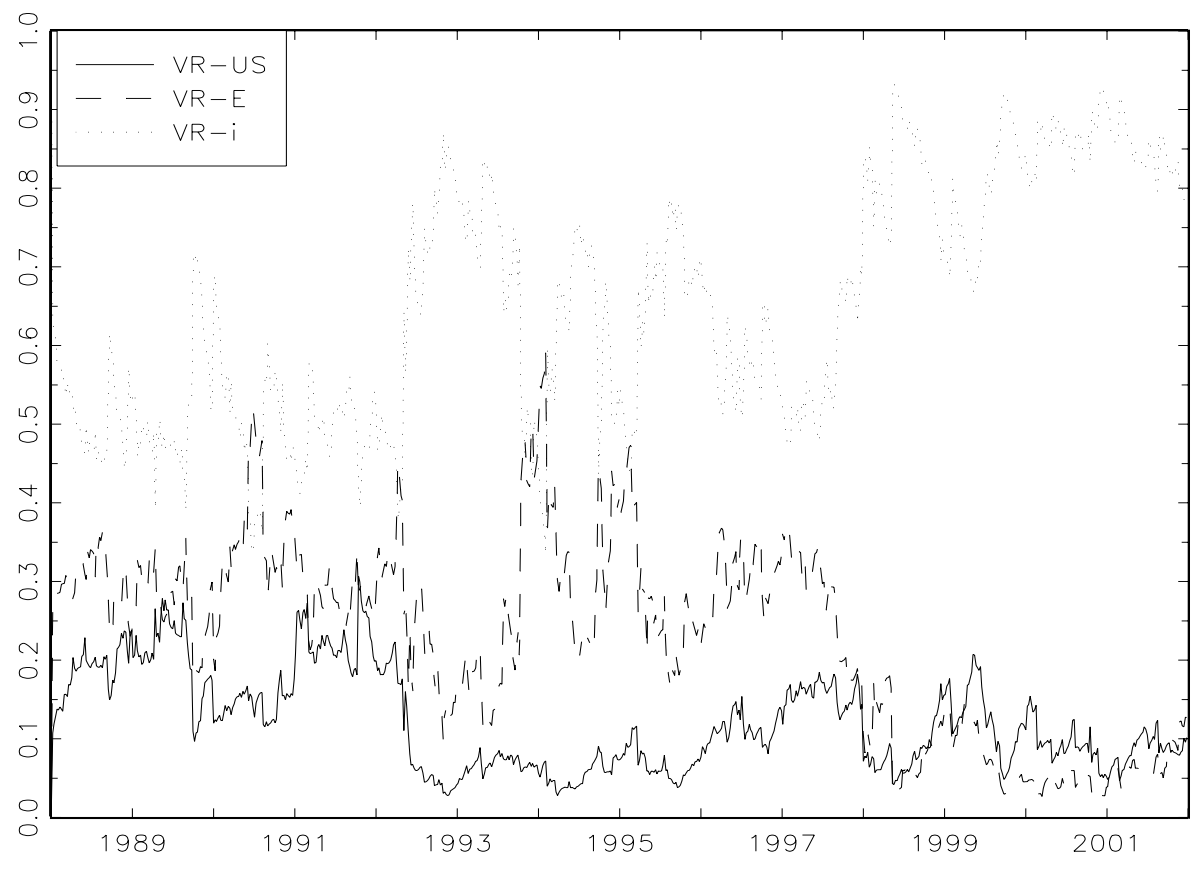

Figure 17: Variance Ratios - Sweden - Euro Spillover Model

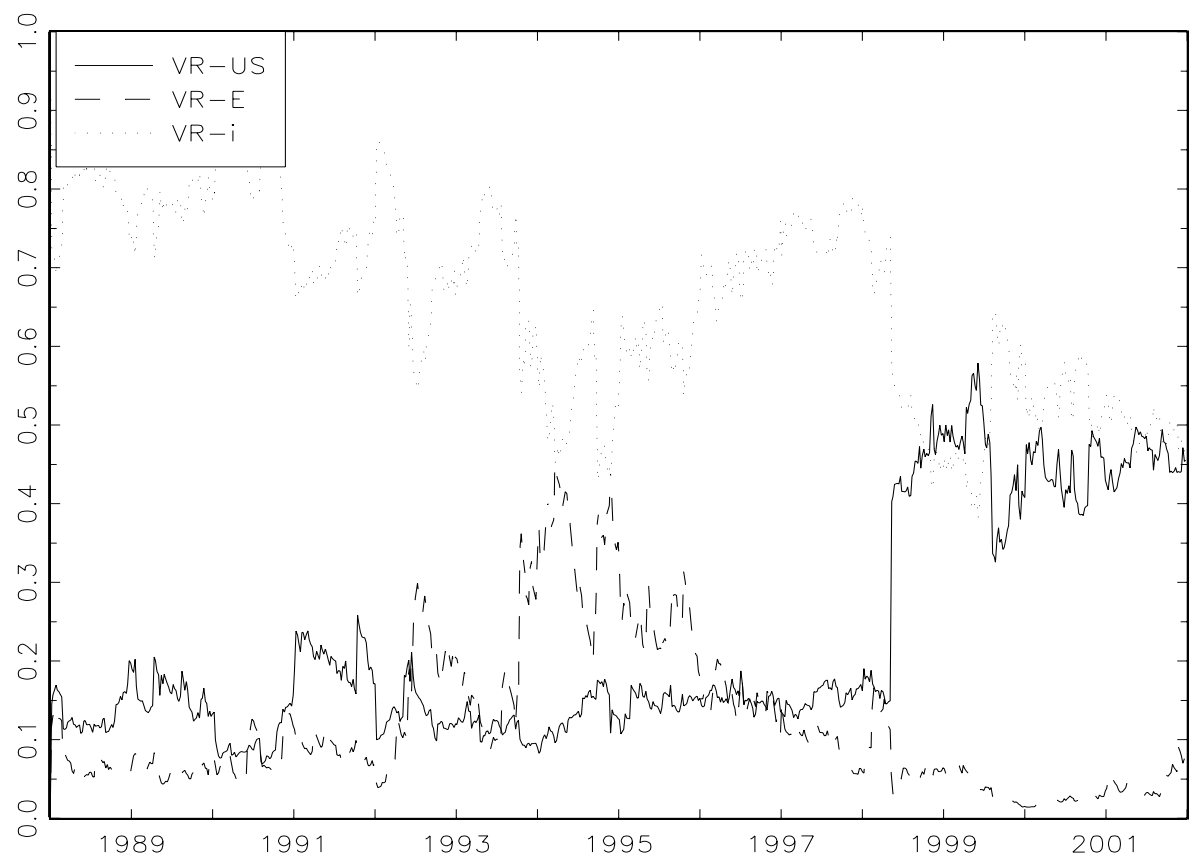

Figure 18: Variance Ratios - United Kingdom - Euro Spillover Model 